NBER WORKING PAPER SERIES

\title{
COST-BENEFIT ANALYSIS OF LEANING AGAINST THE WIND
}

\author{
Lars E.O. Svensson \\ Working Paper 21902 \\ http://www.nber.org/papers/w21902 \\ NATIONAL BUREAU OF ECONOMIC RESEARCH \\ 1050 Massachusetts Avenue \\ Cambridge, MA 02138 \\ January 2016, Revised May 2017
}

Previously circulated as "Cost-Benefit Analysis of Leaning Against the Wind: Are Costs Larger Also with Less Effective Macroprudential Policy?" I thank the editors, the referees, David Aikman, David Archer, Vivek Arora, Tamim Bayoumi, Christoph Bertsch, Helge Berger, Olivier Blanchard, Claudio Borio, Lael Brainard, Giovanni Dell'Ariccia, Andrew Filardo, Stanley Fischer, Kevin Fletcher, Karl Habermeier, Vikram Haksar, Dong He, Olivier Jeanne, Anil Kashyap, Michael Kiley, Jun Il Kim, Luc Laeven, Nellie Liang, Lien Laureys, Stefan Laséen, David López-Salido, Tommaso Mancini Griffoli, Loretta Mester, Edward Nelson, William Nelson, Andrea Pescatori, Bengt Petersson, Rafael Portillo, Pau Rabanal, Phurichai Rungcharoenkitkul, Damiano Sandri, Sunil Sharma, Oreste Tristani, Gregory Thwaites, David Vestin, José Viñals, and participants in seminars at Bank of Canada, Bank of England, Bank of Italy, BIS, ECB, Federal Reserve Board, IMF, NBER Summer Institute, the National Institute of Economic Research, Norges Bank, Sveriges Riksbank, and University of Maryland and in the conference on Macroeconomics and Monetary Policy at the Federal Reserve Bank of San Francisco for helpful discussions and comments. I also thank the IMF and the ECB for their hospitality during, respectively, my visit January 2015-March 2016 as an IMF Research Department Resident Scholar and my visit September-November 2016 as Wim Duisenberg Research Fellow. Any views expressed are those of the author and do not necessarily represent the views of the IMF, the ECB, the Eurosystem, or the NBER. A previous, longer version was published as IMF Working Paper WP/16/3.

NBER working papers are circulated for discussion and comment purposes. They have not been peer-reviewed or been subject to the review by the NBER Board of Directors that accompanies official NBER publications.

(C) 2016 by Lars E.O. Svensson. All rights reserved. Short sections of text, not to exceed two paragraphs, may be quoted without explicit permission provided that full credit, including (C) notice, is given to the source. 
Cost-Benefit Analysis of Leaning Against the Wind

Lars E.O. Svensson

NBER Working Paper No. 21902

January 2016, Revised May 2017

JEL No. E52,E58,G01

\begin{abstract}
$\underline{\text { ABSTRACT }}$
A simple and transparent framework for cost-benefit analysis of "leaning against the wind" (LAW), that is, tighter monetary policy for financial-stability purposes, is presented. LAW has obvious costs in the form of a weaker economy if no crisis occurs and possible benefits in the form of a lower probability and smaller magnitude of (financial) crises. A second cost-less obvious, overlooked by previous literature, but higher-is a weaker economy if a crisis occurs. For representative empirical benchmark estimates and reasonable assumptions the result is that the costs of LAW exceed the benefits by a substantial margin. The result is robust to alternative assumptions and estimates. A higher probability, larger magnitude, or longer duration of crisestypical consequences of ineffective macroprudential policy - all increase the margin of costs over benefits. To overturn the result, policy-interest-rate effects on the probability and magnitude of crises need to be more than 5-40 standard errors larger than the benchmark estimates.
\end{abstract}

Lars E.O. Svensson

Department of Economics

Stockholm School of Economics

P.O. Box 6501

SE-11383 Stockholm

Sweden

and NBER

Leosven@gmail.com 


\section{Contents}

1 Introduction $\quad 1$

2 Theoretical framework $\quad 6$

3 Benchmark numbers $\quad 11$

4 Robustness tests $\quad 19$

5 Conclusions and qualifications $\quad 26$

$\begin{array}{ll}\text { References } & 29\end{array}$

$\begin{array}{ll}\text { Appendix } & 33\end{array}$

A The optimal unemployment rate and the indirect loss function 33

B A cost-push shock correlated with the crisis $\quad 34$

C A Markov process for crisis and non-crisis states $\quad 35$

$\begin{array}{lc}\text { D The logistic function } & 36\end{array}$ 


\section{Introduction}

"Leaning against the wind" (of asset prices and credit booms) (LAW for short) here refers a monetary policy that is somewhat tighter (that is, with a somewhat higher policy interest rate) than what is consistent with flexible inflation targeting without taking any effects on financial stability into account. LAW has obvious costs in terms of a weaker economy with higher unemployment and lower inflation. It has been justified by possible benefits in the form of a lower probability or smaller magnitude of future (financial) crisis (BIS (2014, 2016a), Olsen (2015), Sveriges Riksbank (2013)), although, strikingly, without any credible numerical cost-benefit analysis (Allen et al. (2016)). This paper provides a framework for such an analysis and benchmark numerical estimates of the costs and benefits of LAW. The result is that the costs exceed the benefits by a substantial margin. Extensive robustness tests indicate that this result is quite robust. For example, to overturn the result, the effects of LAW on the probability or magnitude of a crisis need to be more than 5-40 standard errors larger than typical empirical estimates in the literature.

Regarding the costs of LAW, one obvious cost is a weaker economy if no crisis occurs. But there is a second, less obvious but higher cost, overlooked by the previous literature but taken into account in this paper. If a crisis occurs when the economy is weaker because of LAW, for a given magnitude of a crisis the economy will be weaker also in the crisis. Thus, for a given magnitude of a crisis the crisis loss level and the cost of a crisis will be higher with LAW than without.

Consider a simple example in terms of unemployment gaps: First, suppose that without LAW the non-crisis unemployment gap is zero. Suppose that a crisis increases the unemployment gap by 5 percentage points (pp). Then the crisis unemployment gap is $0+5=5 \mathrm{pp}$. With a quadratic loss function the non-crisis loss is $0^{2}=0$, and the crisis loss is $5^{2}=25$. The cost of a crisis, defined as the crisis loss less the non-crisis loss, is $25-0=25$.

Next, suppose that with LAW the non-crisis unemployment gap is $0.5 \mathrm{pp}$ instead of 0 . Then the crisis unemployment gap is $0.5+5=5.5$ pp instead of 5 . The non-crisis loss is $0.5^{2}=0.25$ instead of 0 , and the crisis loss is $5.5^{2}=30.25$ instead of 25 . Then there are two costs of LAW. The first is the non-crisis loss increase, $0.25-0=0.25$. The second is the crisis loss increase, $30.25-25=5.25$. It is the main cost of LAW. The cost of a crisis, the crisis loss less the non-crisis loss, is $30.25-0.25=30$ instead of 25 . The cost of a crisis is higher with LAW than without. In this example, the first cost of LAW is of the second order, whereas the second cost is of the first order. It follows that, for a zero non-crisis unemployment gap, the marginal cost is zero for the 
first cost of LAW but positive for the second cost. Overlooking the second cost misses that the marginal cost of $L A W$ is positive, not zero.

Regarding the possible benefits of LAW (lower probability and smaller magnitude of crises), recent work has emphasized the role of credit growth and credit booms in predicting crises and their magnitude (Borio and Drehmann (2009), Gourinchas and Obstfeld (2012), Schularick and Taylor (2012)). A possible channel for the benefits of LAW is then through an effect of the policy (interest) rate on credit combined with an effect of credit on the probability and magnitude of a crisis. I will use representative empirical estimates surveyed in IMF (2015) of these effects to provide numerical estimates of the benefits of LAW, more precisely Sveriges Riksbank (2014a) estimates of the policyrate effect on debt, Schularick and Taylor (2012) (ST for short) estimates of effect of debt on the probability of a crisis, and Flodén (2014) and Jordà et al. (2013) (JST for short) estimates of the effect of debt on the magnitude of a crisis.

There are, however, at least three limitations of this channel for the benefits of LAW. First, ST show that the probability of a crisis is correlated with lagged growth of real debt or of debt to GDP. But if monetary policy is neutral and has no real effects in the long run, it does not affect real debt or debt to GDP in the long run. Then lower real debt growth and a probability of a crisis will be followed by higher real debt growth and probability of a crisis; the probability is just shifted between periods. The cumulative policy-rate effect on the probability of a crisis and the cumulative marginal benefit from a lower probability of a crisis will then be small or zero. If instead monetary policy is non-neutral and the policy-rate has a permanent negative effect on real debt, the cumulative policy-rate effect on the probability of a crisis will be negative and the cumulative marginal benefit will be positive, stacking the cards in favor of LAW. Including this case is an obvious robustness test, but as shown below, also for monetary non-neutrality the result is that costs of LAW exceed the benefits by a substantial margin.

Second, as discussed in Svensson (2013a), the policy-rate effect on real debt and debt to GDP is likely to be small and could be of either sign. The stock of nominal debt, especially mortgages with long maturities, has considerable inertia. A higher policy rate may slow down the growth of housing prices and of new mortgages, but only a fraction of the stock of mortgages is turned over or each year. A higher policy rate also slows down the growth of the price level. Thus, both numerator and denominator of real debt are affected in the same direction, making the policy-rate effect on the ratio smaller and possibly of the opposite sign. This is even more the case for the debt-to-GDP ratio (a stock divided by a flow) because then not only the price level but also real GDP enter in the 
denominator. The policy-rate effect on the flow of nominal GDP may be larger and quicker than the effect on the stock of nominal debt. Several recent papers have indeed found empirical support for a higher policy-rate increasing rather than decreasing the debt-to-GDP ratio (Alpanda and Zubairy (2014), Bauer and Granziera (2016), Gelain et al. (2015), and Robstad (2014)). Nevertheless, I will use empirical estimates according to which the policy-rate has a negative effect on both real debt and debt to GDP, thereby stacking the cards in favor of LAW.

Third, the correlation between the probability and magnitude of a crisis and previous growth of real debt or debt to GDP is obviously a reduced-form result. The underlying determinants of the probability and magnitude of a financial crisis are mainly the nature of the shocks to the financial system and the resilience of the system. The latter depends in principle on the loss-absorbing capacity and liquidity of lenders, intermediators, and borrowers and the debt-servicing capacity of the borrowers. The extent to which higher debt growth increases the probability of a crisis depends on to what extent it is "bad" credit growth due to, for example, lower lending standards, excessive loan-to-value ratios, and speculation rather than "good" credit growth due to financial deepening, new technology and investment opportunities, and other developments that do not weaken but rather strengthens the financial system. With better data on the underlying determinants of the nature and magnitude of shocks and the resilience of the system, it should be possible to assess the probability and magnitude of a crisis with better precision. However, given the list of possible underlying determinants, it seems that the policy rate is unlikely to have any systematic impact on most or any of them, and that micro- and macroprudential policy is much more likely to have such an impact. ${ }^{1}$

Some of the estimates, in particular of the policy-rate effects on debt growth and debt to GDP, are imprecise, in the sense of having large standard errors relative to the point estimates and not being significant. This makes the estimates of costs and benefits of LAW imprecise. A two-step strategy is used to handle this. First, I choose benchmark point estimates of the effects that are either representative or tilted in favor of LAW. The result for these benchmark estimates turn out to be that costs exceed benefits by a large margin. Second, I examine how robust this result is to

\footnotetext{
1 Bordo and Meissner (2016), in a thorough survey the literature on financial crises, warns that "it is not at all obvious from the historical record that credit-financed asset price boom-bust (i.e., what has come to be known as the financial cycle) have always been, or will always be, the key explanation despite the recent emphasis on that explanation." IMF (2015) discusses the transmission channels from the policy rate to the probability of a crisis and documents its complexity, uncertainty of direction, and variation over time. Dagher et al. (2016) shows that more but still relatively moderate bank capital relative to risk-weighted assets could have had a dramatic effect in reducing the frequency of banking crises in the OECD countries since 1970. Korinek and Simsek (2016) show that macroprudential policies can be quite effective in dealing with excess household debt and that interest-rate policies are likely to be inferior in this respect.
} 
alternative assumptions about the components of the costs and benefits. In particular, I examine how many standard errors larger than the benchmark estimates the effects need to be in order to overturn the result, in the sense of at least reaching break-even, that is, when the costs and benefits of LAW are equal. One might think that the number of standard errors needed would be relatively small, perhaps even less than two, indicating a less than robust result. But the number of standard errors required to reach break-even turns out to be relatively large, ranging from more than 5 to about 40 , indicating a quite robust result.

Related literature The previous literature trying to quantify the costs and benefits of LAW (including Ajello et al. (2016), Svensson (2014, 2015), and IMF (2015)) has mainly considered a two-period setup where a higher policy rate has a cost in the first period in the form of higher unemployment (and lower inflation) and a benefit in the second period in the form of a lower probability of a crisis because of lower debt. By assumption there is no possibility of a crisis in the first period, and by assumption a crisis in the second period would start from a steady state with a zero non-crisis unemployment gap. The crisis unemployment gap and the crisis loss are then assumed to be constant and independent of LAW. This setup disregards that a crisis could come any time while the unemployment is higher due to LAW. It also assumes a fixed rather than endogenous lag between LAW and lower probability of a crisis. Finally, it implicitly assumes that monetary policy is non-neutral and has a permanent effect on real debt. ${ }^{2} 3$

Importantly, by assuming that the crisis loss is constant and independent of the non-crisis unemployment gap, the previous literature disregards the second cost of LAW, the main cost of LAW. In terms of the example above: Suppose again that with LAW the non-crisis unemployment gap is $0.5 \mathrm{pp}$. In the present framework, the crisis unemployment gap, the crisis loss, and the crisis loss increase are then, respectively, $5.5 \mathrm{pp}, 5.5^{2}=30.25$, and $30.25-25=5.25$. In the previous literature, they are instead always, respectively, $5 \mathrm{pp}, 5^{2}=25$, and $25-25=0$, regardless of the non-crisis unemployment gap. This means that in the previous literature the second cost of LAW, the crisis loss increase, will be zero instead of positive. Then, with the first cost being of second order, it follows that, for a zero non-crisis unemployment gap, the marginal cost of LAW will be zero instead of positive. With a positive marginal benefit of LAW, some LAW will then be optimal. But the optimal LAW is very small, corresponding to a policy-rate increase of only a few

\footnotetext{
${ }^{2}$ Diaz Kalan et al. (2015) instead use a quarterly multi-period model where the probability of a crisis varies over time and the costs and benefits of LAW are cumulated over time, as does this paper. They nevertheless still assume that the crisis unemployment gap and the crisis loss level are constant and independent of LAW.

${ }^{3}$ Svensson $(2014,2015)$ did not use a quadratic but a linear loss function in the form of expected unemployment.
} 
basis points (bp), and thus of no practical relevance, as shown by Ajello et al. (2016) and further examined in Svensson (2017b). ${ }^{4}$

The assumption of a constant crisis loss has the counter-intuitive implication that the cost of a crisis, the crisis loss less the non-crisis loss, is decreasing in the non-crisis loss. In particular, if the non-crisis unemployment gap for some reason would be above $5 \mathrm{pp}$, the economy would be better off in a crisis, because then the unemployment gap would drop to $5 \mathrm{pp}$. It trivially follows that the cost of a crisis is lower with LAW than without, because LAW would increase the non-crisis loss without affecting the crisis loss.

After the first version, Svensson (2016a), of this paper was distributed, BIS (2016a, Box IV.B) has disputed its result and argued that it (1) relies on debt growth rather than a "financial cycle" as a predictor of crises, (2) assumes that the magnitude of a crisis is exogenous and independent of the policy rate, and (3) just discusses a one-off policy-rate increase instead of a systematic and optimal policy of LAW.

Regarding (1), it is an empiricial issue what, first, the best predictor of future crises is and, second, what the policy-rate effect on that predictor is. I use real debt growth because of the empirical support of ST and IMF (2015). Nothing prevents the use of a financial cycle instead, if it has better empirical support. ${ }^{5}$ Regarding (2), an endogenous magnitude of a crisis was actually included in Svensson (2016a, appendix D). As in this paper, it does not change the result. Regarding (3), Svensson (2016a, section 3) actually examines optimal policy, not only a one-off policy tightening. ${ }^{6}$ Interestingly, in their review of BIS research, Allen et al. (2016) criticize the BIS for being "excessively focussed on building the case for LAW" and for too much research being "motivated primarily by a desire to overturn [the Svensson (2016a)] conclusion on the inadvisability of LAW."

More recently, Filardo and Rungcharoenkitkul (2016) and Gourio et al. (2016) (FR and GKS for short) have responded to Svensson (2016a), arguing that LAW would be optimal and maintaining that this contradicts my result. However, as discussed in Svensson (2016b, 2017b), their results can be explained by their assumption that the cost of a crisis is constant and independent of LAW. In terms of the simple example above, FR and GKS can be interpreted as assuming that the

\footnotetext{
${ }^{4}$ The reason for the small optimal LAW is that the marginal cost for the first cost of LAW rises quickly with the non-crisis unemployment gap whereas the marginal benefit is flat and relatively small.

${ }^{5}$ However, with the financial cycle as in Drehmann et al. (2012) including real debt and debt to GDP, by the discussion above, the policy-rate effect on it is likely to be small and possibly even of the opposite sign. Consistent with this, the policy-rate impact on the "leverage gap" in Juselius et al. (2016, table 3) is small and not statistically significant.

${ }^{6}$ See also comments on "calculus of variations" in section 5 below.
} 
unemployment gap is not affected by a crisis and that there is a separate constant cost of a crisis (the crisis loss less the non-crisis loss) that is always 25, regardless of the non-crisis unemployment gap. Then, without LAW, the non-crisis loss is zero and the crisis loss is 25. With LAW, the non-crisis loss is 0.25 , and the crisis loss is $0.25+25=25.25$. The first cost of LAW, the non-crisis loss increase, is $0.25-0=0.25$. The second cost, the crisis loss increase, is $25.25-25=0.25$, equal to the first. Thus, although the second cost is not zero, as when a constant crisis loss is assumed, it is as small as the first and thus of second order.

Their assumption then has the same implications as the assumption of a constant crisis loss. For a zero non-crisis unemployment gap, the marginal cost of LAW is zero, whereas the marginal benefit is positive. Some LAW is then optimal. But again, as shown in Svensson (2017b) and for a constant crisis loss in Ajello et al. (2016), the optimal LAW is very small, only a few basis points. Consistent with this, GKS find that the optimal LAW leads to a reduction of the annual probability of only 6 bp from $2.08 \%$ to $2.02 \%$, implying on average one crisis in 49.5 years instead of one in 48.1 years. This is hardly economically significant. ${ }^{7}$

Finally, Adrian and Liang (2017) (AL for short) have challenged the robustness of my result and argued that alternative reasonable assumptions about the effect of the policy rate on the probability or magnitude of a crisis would overturn it. However, as is shown in Svensson (2017a) and below, AL's alternative assumptions required to overturn my result imply an effect of debt on the magnitude of a crisis that is more than 40 standard errors larger than the estimate of Flodén (2014) and more than 11 standard errors larger than an estimate that follows from JST, or an effect of credit on the probability of a crisis that is more than 13 standard errors larger than the estimate of $\mathrm{ST}^{8}$

In summary, relative to the previous literature this paper takes into account the second cost of LAW, the crisis loss increase. It also clarifies the role of monetary neutrality and non-neutrality.

\footnotetext{
${ }^{7}$ As shown in Svensson (2017b), with the assumption of a constant cost of a crisis in the present framework, the reduction in the annual probability of a crisis is $4 \mathrm{bp}$, quite similar to the GKS result. Furthermore, GKS assess whether LAW is beneficial by examining whether the loss is reduced if an additional variable is added as an argument to a Taylor-type rule, namely "inefficient credit," which variable is assumed to affect the probability of a crisis. But Taylor-type rules are suboptimal; they have too few arguments. Optimal policy normally requires responding to all state variables, including shocks. Adding an argument to a suboptimal policy rule, as is common in many papers on monetary policy, means that the set of arguments better span the space of state variables and shocks. It is therefore not surprising if adding an argument, normally any argument correlated with left-out state variables, reduces loss.

${ }^{8}$ Sutherland et al. (2012) and Mian et al. (2016) (cited by AL) examine and estimate the possible effect of credit on the magnitude of downturns in recessions. But, importantly, the estimates that are relevant here are of the possible effect of credit on the magnitude of a financial crisis, that is, the effect on the downturn conditional on a financial crisis, not the possible effect of credit on the unconditional downturn in a general recession, regardless of whether there is a financial crisis or not. In a similar line, Adrian and Duarte (2016) examine possible effects of the policy rate on the volatility of GDP, regardless of whether there is a financial crisis or not. This is about a possible aspect of the transmission mechanism that violates certainty equivalence, but this is a different issue from what is discussed in this paper. Thus, in contrast to what they state, their findings do not contradict but are rather, as far as I can see, orthogonal to the result in this paper.
} 
In particular, it provides a simple, transparent, and robust framework for cost-benefit analysis of LAW that only depends on a few assumptions and empirical estimates. It furthermore provides several robustness tests, including some that handle imprecise estimates.

Outline Section 2 lays out the theoretical framework, section 3 specifies benchmark estimates and assumptions, section 4 provides robustness tests, and section 5 present conclusions and some qualifications. Appendices A-D include some technical details.

\section{Theoretical framework}

This section sets up the theoretical framework used to assess the costs and benefits of LAW. Let $u_{t}$ denote the unemployment rate in quarter $t \geq 1$, and let $u_{t}^{*}$ denote the optimal unemployment rate under flexible inflation targeting when the possibility of a financial crisis is disregarded. By flexible inflation targeting I mean a monetary policy under which the central bank stabilizes both the inflation rate around an inflation target and the unemployment rate around its long-run sustainable rate. Exogenous cost-push shocks to the Phillips curve create a tradeoff between stabilizing the inflation rate and stabilizing the unemployment rate. Then the optimal unemployment rate depends on the cost-push shocks, and varies over time. It will here be called the benchmark unemployment rate.

Let the unemployment deviation, $\tilde{u}_{t}$, be defined as the gap between the unemployment rate and the benchmark unemployment rate, $\tilde{u}_{t} \equiv u_{t}-u_{t}^{*}$. Thus the unemployment deviation is not the deviation from the steady state (or the unemployment gap as in the simple example in sectison 1) but the devation from the optimal policy under flexible inflation targeting when the probability of a crisis is set to zero. As explained in appendix A, the loss from the unemployment rate deviating from the benchmark unemployment rate can be represented by the simple quadratic (indirect) loss function,

$$
L_{t}=\left(\tilde{u}_{t}\right)^{2}
$$

where $L_{t}$ denotes the quarter- $t$ (simple) loss. ${ }^{9}$ The quarter-1 intertemporal loss function for monetary policy is

$$
\mathcal{L}_{1}=\mathrm{E}_{1} \sum_{t=1}^{\infty} \delta^{t-1} L_{t}=\sum_{t=1}^{\infty} \delta^{t-1} \mathrm{E}_{1} L_{t}
$$

\footnotetext{
${ }^{9}$ The "true" loss function is then an affine function of the simple loss function.
} 
where $\mathrm{E}_{1}$ denotes expectations conditional on information available in quarter $1, \delta \in(0,1)$ denotes a discount factor, and $\mathrm{E}_{1} L_{t}$ denotes the expected quarter- $t$ loss for $t \geq 1$.

The expected quarter- $t$ loss will be given by

$$
\mathrm{E}_{1} L_{t}=\mathrm{E}_{1}\left(\tilde{u}_{t}\right)^{2}=\left(1-p_{t}\right) \mathrm{E}_{1}\left(\tilde{u}_{t}^{\mathrm{n}}\right)^{2}+p_{t} \mathrm{E}_{1}\left(\tilde{u}_{t}^{\mathrm{c}}\right)^{2} \equiv\left(1-p_{t}\right) \mathrm{E}_{1}\left(\tilde{u}_{t}^{\mathrm{n}}\right)^{2}+p_{t} \mathrm{E}_{1}\left(\tilde{u}_{t}^{\mathrm{n}}+\Delta u_{t}\right)^{2} .
$$

Here it is assumed that, in quarter $t \geq 2$, there can be either of two states of the world, namely either a non-crisis or a (financial) crisis, denoted $\mathrm{n}$ and $\mathrm{c}$, respectively. By assumption, there is no crisis in quarter 1. Furthermore, $p_{t}$ denotes the probability of (having) a crisis in quarter $t$, conditional on information available in quarter 1 . The variable $\tilde{u}_{t}^{\mathrm{n}}$ denotes the quarter- $t$ non-crisis unemployment deviation, that is, the unemployment deviation if there is no crisis in the quarter. Then the first term of the right side of (2.3) is the probability of no crisis, $1-p_{t}$, times the expected non-crisis loss, $\mathrm{E}_{1} L_{t}^{\mathrm{n}}=\mathrm{E}_{1}\left(\tilde{u}_{t}^{\mathrm{n}}\right)^{2}$, that is, the expected loss if there is no crisis in quarter $t$.

The second term on the right side of (2.3) is the probability of a crisis times the expected crisis loss, $\mathrm{E}_{1} L_{t}^{\mathrm{c}}=\mathrm{E}_{1}\left(\tilde{u}_{t}^{\mathrm{c}}\right)$, that is, the expected loss if there is a crisis in quarter $t$. A crisis is assumed to be associated with a (possibly random) crisis increase in the unemployment rate, $\Delta u_{t}>0$, so the crisis unemployment deviation is $\tilde{u}_{t}^{\mathrm{c}} \equiv \tilde{u}_{t}^{\mathrm{n}}+\Delta u_{t}$, and the crisis loss is $L_{t}^{\mathrm{c}}=\mathrm{E}_{1}\left(\tilde{u}_{t}^{\mathrm{c}}\right)^{2} \equiv \mathrm{E}_{1}\left(\tilde{u}_{t}^{\mathrm{n}}+\Delta u_{t}\right)^{2}$. This crisis increase in the unemployment rate is net of any policy response during a crisis. Thus, $\Delta u_{t}$ can be interpreted as the unemployment-rate increase that is equivalent to the combination of a demand shock and any shock to the transmission mechanism of monetary policy associated with a crisis, net of the conventional and unconventional policy response at a crisis, including any restriction on the policy response such as the lower bound of the policy rate. It represents the magnitude of a crisis. ${ }^{10}$

Equation (2.3) can be written as ${ }^{11}$

$$
\mathrm{E}_{1} L_{t}=\mathrm{E}_{1}\left(\tilde{u}_{t}^{\mathrm{n}}\right)^{2}+p_{t}\left[\mathrm{E}_{1}\left(\tilde{u}_{t}^{\mathrm{n}}+\Delta u_{t}\right)^{2}-\mathrm{E}_{1}\left(\tilde{u}_{t}^{\mathrm{n}}\right)^{2}\right]=\mathrm{E}_{1}\left(\tilde{u}_{t}^{\mathrm{n}}\right)^{2}+p_{t}\left[\mathrm{E}_{1}\left(\Delta u_{t}\right)^{2}+2 \mathrm{E}_{1} \tilde{u}_{t}^{\mathrm{n}} \mathrm{E}_{1} \Delta u_{t}\right]
$$

Here, the expression in square brackets in (2.4) is the (expected) cost of a crisis, that is, the (expected) crisis loss less the (expected) noncrisis loss. We see in the square brackets on the

\footnotetext{
10 The benchmark assumption is for simplicity that the benchmark unemployment rate, $u_{t}^{*}$, is independent of whether there is a crisis or not, in which case $\Delta u_{t}$ is the crisis increase in the unemployment rate. As explained in appendix $\mathrm{B}$, if the benchmark unemployment rate is correlated with a crisis, the crisis increase in the unemployment rate and in the unemployment deviation are not the same. Then $\Delta u_{t}$ is the crisis increase in the unemployment deviation and equals the crisis increase in the unemployment rate less the crisis increase in the benchmark unemployment rate. Because the benchmark unemployment rate is increasing in cost-push shocks to the Phillips curve and such cost-push shocks are likely to be negative in a crisis, any crisis increase in the benchmark unemployment rate is likely to be negative.

${ }^{11}$ I assume that $\mathrm{E}_{1}\left(\tilde{u}_{t}^{\mathrm{n}} \Delta u_{t}\right)=\mathrm{E}_{1} \tilde{u}_{t}^{\mathrm{n}} \mathrm{E}_{1} \Delta u_{t}$, that is, $\tilde{u}_{t}^{\mathrm{n}}$ and $\Delta u_{t}$ are uncorrelated conditional on information available in quarter 1.
} 
right side of (2.4) that the (expected) cost of a crisis is increasing in the (expected) non-crisis unemployment deviation, $\mathrm{E}_{1} \tilde{u}_{t}^{\mathrm{n}}$. (For brevity and when no confusion need arise, "expected" will often be left out but understood in the rest of the paper.)

As explained above, a zero non-crisis unemployment deviation corresponds to the optimal policy under flexible inflation targeting when the possibility of a crisis is disregarded, that is, when the probability of a crisis is set to zero. This can be seen as a policy of no leaning (NL for short). A positive non-crisis unemployment deviation corresponds to tighter policy than NL and can thus be seen as representing LAW. A negative non-crisis unemployment deviation corresponds to easier policy than NL and can be seen as representing leaning with the wind (LWW for short).

Consider the effect on the intertemporal loss (2.2) of a policy tightening in the form of an increase in the policy rate during quarters $1-4$, denoted $d \bar{i}_{1}>0$. The cumulative net marginal cost of LAW, NMC, is defined as the derivative of the intertemporal loss with respect to the policy rate during quarters $1-4, \mathrm{NMC} \equiv d \mathcal{L}_{1} / d \bar{i}_{1}=\left(d / d \bar{i}_{1}\right) \mathrm{E}_{1} \sum_{t=1}^{\infty} \delta^{t-1} L_{t}=\sum_{t=1}^{\infty} \delta^{t-1} d \mathrm{E}_{1} L_{t} / d \bar{i}_{1}$.

Furthermore, define the quarter- $t$ net marginal cost, $\mathrm{NMC}_{t}$, as $d \mathrm{E}_{1} L_{t} / d \bar{i}_{1}$, the policy-rate effect on the quarter-t expected loss. Taking the derivative of the right side of (2.4) with respect to $\bar{i}_{1}$ gives $\mathrm{NMC}_{t} \equiv \mathrm{MC}_{t}-\mathrm{MB}_{t}$, where

$$
\begin{aligned}
\mathrm{MC}_{t} & \equiv 2\left(\mathrm{E}_{1} \tilde{u}_{t}^{\mathrm{n}}+p_{t} \mathrm{E}_{1} \Delta u_{t}\right) \frac{d \mathrm{E}_{1} u_{t}^{\mathrm{n}}}{d \bar{i}_{1}}=\left.2 \mathrm{E}_{1} \tilde{u}_{t} \frac{d \mathrm{E}_{1} \tilde{u}_{t}}{d \bar{i}_{1}}\right|_{p_{t}, \mathrm{E}_{1} \Delta u_{t}=\text { const. }} \\
\mathrm{MB}_{t}^{p} & \equiv\left[\mathrm{E}_{1}\left(\Delta u_{t}\right)^{2}+2 \mathrm{E}_{1} \tilde{u}_{t}^{\mathrm{n}} \mathrm{E}_{1} \Delta u_{t}\right]\left(-\frac{d p_{t}}{d \bar{i}_{1}}\right), \\
\mathrm{MB}_{t}^{\Delta u} & \equiv 2 p_{t} \mathrm{E}_{1}\left(\tilde{u}_{t}^{\mathrm{n}}+\Delta u_{t}\right)\left(-\frac{d \mathrm{E}_{1} \Delta u_{t}}{d \bar{i}_{1}}\right)=2 p_{t} \mathrm{E}_{1} \tilde{u}_{t}^{\mathrm{c}}\left(-\frac{d \mathrm{E}_{1} \Delta u_{t}}{d \bar{i}_{1}}\right), \\
\mathrm{MB}_{t} & \equiv \mathrm{MB}_{t}^{p}+\mathrm{MB}_{t}^{\Delta u}
\end{aligned}
$$

Here $\mathrm{MC}_{t}$ denotes the marginal cost of $L A W$. It consists of the marginal increase in the expected quarter- $t$ loss from an increase in the unemployment deviation at constant probability and magnitude of a crisis. By (2.5) it equals two times the unemployment deviation $\left(\mathrm{E}_{1} \tilde{u}_{t}=\right.$ $\left.\mathrm{E}_{1} \tilde{u}_{t}^{\mathrm{n}}+p_{t} \mathrm{E}_{1} \Delta u_{t}\right)$ times the policy-rate effect on the non-crisis unemployment rate, which equals the policy-rate effect on the unemployment deviation for constant probability and magnitude of a crisis $\left(d \mathrm{E}_{1}\left[\tilde{u}_{t} \mid p_{t}, \mathrm{E}_{1} \Delta u_{t}=\right.\right.$ const. $\left.] / d \bar{i}_{1}=d \mathrm{E}_{1} \tilde{u}_{t}^{\mathrm{n}} / d \bar{i}_{1}=d \mathrm{E}_{1} u_{t}^{\mathrm{n}} / d \bar{i}_{1}\right) \cdot{ }^{12}$

Furthermore, $\mathrm{MB}_{t}^{p}$ denotes the marginal benefit of $L A W$ from a lower probability of a crisis. It consists of the marginal reduction of the expected quarter- $t$ loss from a lower probability of a crisis

\footnotetext{
${ }^{12} \mathrm{I}$ assume that $\mathrm{E}_{1}\left(\tilde{u}_{t} d u_{t}^{\mathrm{n}} / d \bar{i}_{1}\right)=\mathrm{E}_{1} \tilde{u}_{t} d \mathrm{E}_{1} u_{t}^{\mathrm{n}} / d \bar{i}_{1}$, that is, that $\tilde{u}_{t}$ and $d u_{t}^{\mathrm{n}} / d \bar{i}_{1}$ are independent conditional on information available in quarter 1 . Furthermore, I have used that, because $u_{t}^{*}$ depends on cost-push shocks and is exogenous, $d \mathrm{E}_{1} \tilde{u}_{t}^{\mathrm{n}} / d \bar{i}_{1}=d \mathrm{E}_{1}\left(u_{t}^{\mathrm{n}}-u_{t}^{*}\right) / d \bar{i}_{1}=d \mathrm{E}_{1} u_{t}^{\mathrm{n}} / d \bar{i}_{1}$.
} 
at a constant non-crisis unemployment deviation and a constant magnitude of a crisis. By (2.6) it equals the crisis loss increase times the negative of the policy-rate effect on the probability of a crisis.

Similarly, $\mathrm{MB}_{t}^{\Delta u}$ denotes the marginal benefit of LAW from a smaller magnitude of a crisis. It consists of the marginal reduction of the expected quarter- $t$ loss from a smaller magnitude of a crisis at constant probability of a crisis and constant non-crisis unemployment deviation. By (2.7) it equals two times the probability of a crisis times the crisis unemployment deviation times the negative of the policy-rate effect on the magnitude of the crisis. $\mathrm{MB}_{t}$ denotes the total marginal benefit, the sum of the two components.

For a zero (expected) non-crisis unemployment deviation $\left(\mathrm{E}_{1} \tilde{u}_{t}^{\mathrm{n}}=0\right)$, the marginal cost and the two marginal benefits are given by

$$
\begin{aligned}
\mathrm{MC}_{t} & =2 p_{t} \mathrm{E}_{1} \Delta u_{t} \frac{d \mathrm{E}_{1} u_{t}^{\mathrm{n}}}{d \bar{i}_{1}} \\
\mathrm{MB}_{t}^{p} & =\mathrm{E}_{1}\left(\Delta u_{t}\right)^{2}\left(-\frac{d p_{t}}{d \bar{i}_{1}}\right) \\
\mathrm{MB}_{t}^{\Delta u} & =2 p_{t} \mathrm{E}_{1} \Delta u_{t}\left(-\frac{d \mathrm{E}_{1} \Delta u_{t}}{d \bar{i}_{1}}\right)
\end{aligned}
$$

In order to assess whether LAW or LWW is preferable when all quarters are considered, we then look at the sign of the cumulative discounted net marginal cost,

$$
\mathrm{NMC}=\sum_{t=1}^{\infty} \delta^{t-1} \mathrm{NMC}_{t}=\sum_{t=1}^{\infty} \delta^{t-1} \mathrm{MC}_{t}-\sum_{t=1}^{\infty} \delta^{t-1} \mathrm{MB}_{t} \gtrless 0,
$$

where $\mathrm{MC}_{t}$ is given by (2.9) and $\mathrm{MB}_{t}$ by (2.8), (2.10), and (2.11).

The case of exogenous probability and magnitude of a crisis: LWW! Assume now temporariliy that the probability and magnitude of a crisis are exogenous, in the sense that they cannot be affected directly or indirectly by the policy rate and LAW. That is, $d p_{t} / d \bar{i}_{1} \equiv d \mathrm{E}_{1} \Delta u_{t} / d \bar{i}_{1} \equiv 0$ for all $t \geq 1$. It then follows from (2.6) and (2.7) that $\mathrm{MB}_{t}^{p} \equiv \mathrm{MB}_{t}^{\Delta u_{t}} \equiv 0$; there are no marginal benefits of LAW, only the marginal cost, given by (2.5).

The optimal policy would then be, if possible, to set each expected future unemployment deviation equal to zero, $\mathrm{E}_{1} \tilde{u}_{t}=\mathrm{E}_{1} u_{t}^{\mathrm{n}}+p_{t} \mathrm{E}_{1} \Delta u_{t}=0$, which by (2.5) would make each future marginal cost equal to zero and minimize each quarter- $t$ expected loss. But, for a positive future probability of a crisis, $p_{t}>0$, this implies setting the expected future non-crisis unemployment deviation negative,

$$
\mathrm{E}_{1} u_{t}^{\mathrm{n}}=-p_{t} \mathrm{E}_{1} \Delta u_{t}<0 .
$$


That is, if the probability and the magnitude of a crisis are exogenous, it is optimal to lean with the wind, LWW, in the sense of setting a lower unemployment rate than the rate that is optimal if the probability of a crisis is set to zero. If the probability and magnitude of a crisis are not exogenous but can be affected by LAW, the issue is then whether any resulting marginal benefits of lower probability or smaller magnitude of a crisis can be so high as to dominate over the marginal cost and make LAW optimal instead of LWW.

\section{Benchmark numbers}

In order to asses whether or not the costs of LAW exceed the benefit, we need numerical estimates of or assumptions about the components of the marginal cost and benefits in (2.9)-(2.11), that is, $p_{t}, \mathrm{E}_{1} \Delta u_{t}, d \mathrm{E}_{1} u_{t}^{\mathrm{n}} / d \bar{i}_{1}, \mathrm{E}_{1}\left(\Delta u_{t}\right)^{2}, d p_{t} / d \bar{i}_{1}$, and $d \mathrm{E}_{1} \Delta u_{t} / d \bar{i}_{1}$.

The marginal cost of LAW For a numerical estimate of the marginal cost of LAW, by (2.9) we need representative estimates of or realistic assumptions about the probability of a crisis, the (expected) magnitude of a crisis, and the policy-rate effect on the (expected) non-crisis unemployment rate.

As a representative benchmark policy-rate effect on the (expected) non-crisis unemployment rate, $d \mathrm{E}_{1} u_{t}^{\mathrm{n}} / d \bar{i}_{1}$, I will use the impulse response of the Riksbank's empirical DSGE model Ramses to a 1 pp higher policy rate during quarters 1-4, shown as the dashed red line in the lower right part of figure 3.1. ${ }^{13}$ The unemployment rate increases above the baseline to about 0.5 pp in quarters $6-8$ and then slowly falls back towards the baseline. For an initial zero non-crisis unemployment deviation, the dashed red line then also shows the effect of the policy rate on the non-crisis unemployment deviation.

This impulse response has a typical and realistic hump-shaped form. Because the economy responds with a lag to policy-rate changes, the initial effect is approximately zero and the maximum effect is reached after 6-8 quarters. It is similar in shape and magnitude to the impulse response reported by IMF (2015, para. 40 and footnote 42) for its widely used GIMF model for an average of a large, mostly closed economy and a small open economy. It is also similar in shape but larger in magnitude than the impulse response of the unemployment rate for the U.S. reported in Stock

\footnotetext{
13 The figure shows the impulse response for 40 quarters of the unemployment rate that was reported by Riksbank Deputy Governor Karolina Ekholm in Ekholm (2013). It is the same response as the one reported to alternative policy-rate paths for quarters 1-12 in Sveriges Riksbank (2014b).
} 
and Watson (2001, figure 1). ${ }^{14}$ The result for a smaller policy-rate effect is examined in section 4 .

For the benchmark (expected) crisis increase in the unemployment rate, $\mathrm{E}_{1} \Delta u_{t}$, representing the magnitude of a crisis, I will for simplicity use the same assumption as in a crisis scenarios discussed in IMF (2015, para. 41) and in Sveriges Riksbank (2013), that the benchmark crisis increase in the unemployment rate is deterministic and constant and equal to $5 \mathrm{pp}$. The result for a larger magnitude of crisis is examined in section 4 .

For a zero non-crisis unemployment devia-

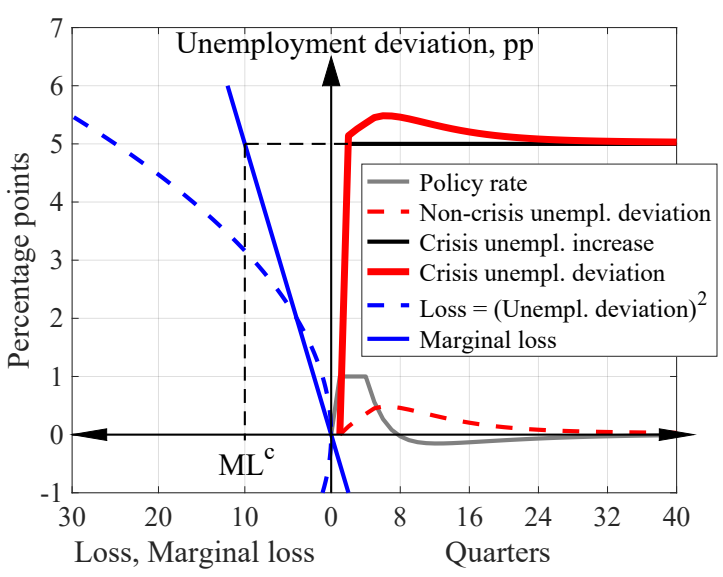

Figure 3.1: The policy-rate effect on the non-crisis and crisis unemployment deviations, and the loss and marginal loss tion, if a crisis occurs, the unemployment deviation would then increase to a crisis unemployment deviation of 5 pp, illustrated by the solid black horizontal line in the upper right part of figure 3.1. Furthermore, with LAW and a positive non-crisis unemployment deviation, if a crisis occurs, the unemployment deviation would increase above $5 \mathrm{pp}$, as shown by the thick solid red line in the figure. Importantly, LAW leads to a higher crisis unemployment deviation, not only to a higher non-crisis unemployment deviation.

The dashed and solid blue lines in the left part of the figure show the loss and marginal loss (with respect to the unemployment deviation), $L_{t}=\left(\tilde{u}_{t}\right)^{2}$ and $\mathrm{ML}_{t} \equiv d L_{t} / d \tilde{u}_{t}=2 \tilde{u}_{t}$, respectively, measured along the horizontal line to the left of the origin. For a zero non-crisis unemployment deviation, the marginal loss of increasing the non-crisis unemployment deviation is zero. At a positive crisis unemployment deviation equal to $\Delta u=5 \mathrm{pp}$, the marginal loss of increasing the crisis unemployment deviation is not zero but positive, $\mathrm{ML}^{\mathrm{c}}=2 \Delta u=10$, as shown in the figure. It follows that the marginal crisis loss with respect an increase in the policy rate, $d L^{\mathrm{c}} / d \bar{i}_{1}=$ $\mathrm{ML}^{\mathrm{c}} d \mathrm{E}_{1} u_{t}^{\mathrm{c}} / d \bar{i}_{1}=2 \Delta u d \mathrm{E}_{1} u_{t}^{\mathrm{n}} / d \bar{i}_{1}$ is positive. When multiplied by the probability of a crisis, it equals the marginal cost of LAW in (2.9).

It remains to specify the benchmark probability of a crisis, $p_{t}$. I will assume that there is a benchmark annual probability of a crisis start equal to $3.2 \%$, corresponding to a crisis on average

\footnotetext{
${ }^{14}$ It is natural that the policy-rate effect on the unemployment rate is larger in a small open economy, with a strong exchange-rate channel in the transmission of monetary policy, than in a large relatively closed economy like the U.S. Stock and Watson's impulse response peaks at $0.2 \mathrm{pp}$ at around 8 quarters, but the cumulative interest-rate impulse is smaller than in figure 3.1. (In figure 3.1 there is an interest-rate impulse in all four quarters 1-4, in order to hold the policy rate $1 \mathrm{pp}$ higher than the baseline for the four quarters.) With a larger and similar cumulative impulse response, Stock and Watson's peak might be around 0.25-0.3 pp rather than of 0.2.
} 
every 31 years. Let $q_{t}$ denote the (quarterly) probability of crisis start in quarter $t$. The benchmark (quarterly) probability of a crisis start is thus $q_{t}=3.2 / 4=0.8 \%$.

Let $n$ denote the crisis duration measured in quarters. The benchmark crisis duration is assumed to be $n=8$ quarters. Combined with the benchmark crisis increase in the unemployment rate, a benchmark crisis then corresponds to a substantial 10 point-years of excess unemployment. The result for a longer crisis duration is examined in section 4.

In figure 3.2 , the thin blue and thick green lines show the benchmark probability of a crisis

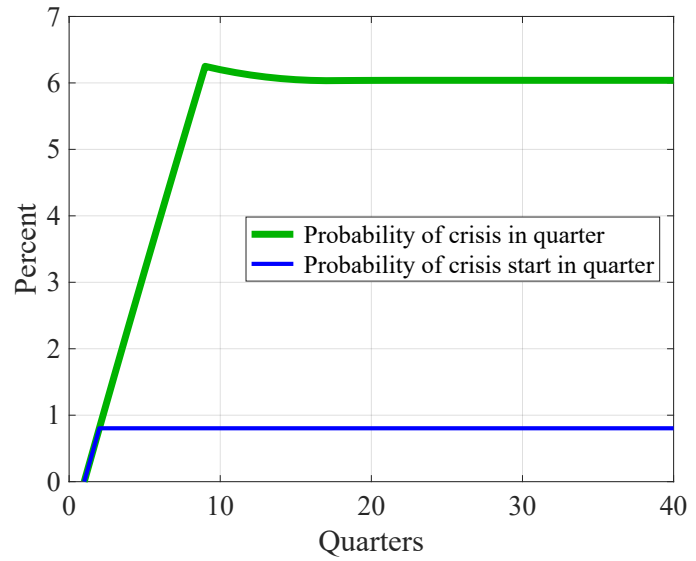

Figure 3.2: The benchmark probabilities of a crisis and a crisis start start and benchmark probability of a crisis in future quarters, conditional on no crisis in quarter 1. The probability of a crisis is equal to the probability of a crisis starting in the last $n$ quarters. This is close to a simple linear approximation used in Svensson (2016a), equal to the sum of the probabilities of a crisis start over the last $n$ quarters, $p_{t} \approx \sum_{\tau=0}^{n-1} q_{t-\tau}$. As explained in appendix C, the exact probability of a crisis, used in this paper, is given by a Markov process. As shown in figure 3.2 , it rises to $6.25 \%$ in quarter 9 and then falls back to a steady-state level of $6 \%$ from quarter $14 .^{15}$ The result for a higher probability of a crisis start and a crisis is examined in section 4 .

In section 2, we noted that for the case of exogenous probability and magnitude of a crisis, the optimal policy is LWW, to set each future expected non-crisis unemployment deviation negative according to (2.13). For the benchmark steady-state probability of $6 \%$ and crisis increase in the unemployment rate of $5 \mathrm{pp}$, the optimal non-crisis unemployment deviation is minus 30 basis points, arguably too small to have any practical importance. But for LAW to be optimal, this tendency towards LWW has to be overcome by sufficiently high marginal benefits of LAW.

All the components of the benchmark marginal cost, (2.9), have now been specified. It is thus given by $\mathrm{MC}_{t}=2 p_{t} \Delta u d \mathrm{E}_{1} u_{t}^{\mathrm{n}} / d \bar{i}_{1}=10 p_{t} d \mathrm{E}_{1} u_{t}^{\mathrm{n}} / d \bar{i}_{1}$ and is shown as the thin solid the red line in figure 3.5 .

\footnotetext{
${ }^{15}$ The linear approximation rises to a steady-state level of $6.4 \%$ in quarter 9, see figure C.1. For the Markov process, it is assumed that a new crisis does not start during an existing crisis, which in steady state reduces the probability of a crisis somewhat from the linear approximation.
} 
The marginal benefit from a lower probability of a crisis For the benchmark marginal benefit from a lower probability of a crisis, (2.10), we need an estimate of the policy-rate effect on the probability of a crisis, $d p_{t} / d \bar{i}_{1}$, which in turn depends on the policy-rate effect on the probability of a crisis start, $d q_{t} / d \bar{i}_{1}$, as shown in appendix C. For a benchmark estimate of the latter, I will combine a benchmark estimate of the effect of debt on the probability of a crisis start with a benchmark estimate of the policy-rate effect on debt.

The effect of debt on the probability of a crisis start In a seminal paper, Schularick and Taylor (2012) (ST for short), using annual data for 14 developed countries for 1870-2008, find that financial crises are predicted by real debt growth lagged 1-5 years. During the work on IMF (2015), IMF staff used a quarterly dataset of Laeven and Valencia (2012) for 35 advanced countries and a more recent sample period, 1970-2011, to predict financial crises. As shown in detail in Svensson (2016a, section 7), the IMF estimates lead to very similar results as the ST estimates. ${ }^{16}$

As a benchmark, I will thus use the estimates of ST (table 3, specification 5), in a quarterly variant of their their main logit regression,

$$
\begin{gathered}
q_{t}=\frac{1}{4} \frac{\exp \left(X_{t}\right)}{1+\exp \left(X_{t}\right)}, \\
X_{t}=-3.89-\underset{(2.110)}{0.398} g_{t-4}+\underset{(2.631)}{7.138^{* * *}} g_{t-8}+\underset{(2.948)}{0.888} g_{t-12}+\underset{(1.378)}{0.203} g_{t-16}+\underset{(1.640)}{1.867} g_{t-20} .
\end{gathered}
$$

Here numbers within parenthesis are robust standard errors ${ }^{17}$ and $g_{t}$ denotes the annual growth rate of (average annual) real debt, defined as $g_{t} \equiv \log \left(\sum_{\tau=0}^{3} d_{t-\tau} / 4\right)-\log \left(\sum_{\tau=0}^{3} d_{t-4-\tau} / 4\right)$, where $d_{t}$ denotes the level of real debt in quarter $t .{ }^{18}$ The coefficients of the five lags are jointly significant at the $1 \%$ level. However, annual real debt growth lagged 2 years, $g_{t-8}$, has the largest and most significant coefficient in (3.2) and is thus the major determinant of the probability of a crisis start.

The policy-rate effect on debt Given a benchmark for the effect of debt on the probability of a crisis start, we need a benchmark for the policy-rate effect on real debt. IMF (2015, para. 24 and footnote 19) summarizes the estimates of this effect in several papers. It notes that "real debt levels generally decrease following a temporary monetary policy tightening of 100 basis points, by up to $0.3 \%$ and $2 \%$, after 4 to 16 quarters, depending on the model" and that "Sveriges Riksbank (2014a) comes to a middle-of-the-road result."

\footnotetext{
16 I am grateful to Damiano Sandri for help with and several discussions about the IMF estimates.

17 One, two, and three stars denote significance at the 10, 5, and $1 \%$ level, respectively.

18 What is called real debt here is in ST total bank loans, defined as the end-of-year amount of outstanding domestic currency lending by domestic banks to domestic households and nonfinancial corporations (excluding lending within the financial system) deflated by the CPI.
} 
As a benchmark, I will thus use the Sveriges Riksbank (2014a) estimate of the policy-rate effect on real (household) debt from a 1 pp higher policy rate during 4 quarters. It is shown as the red line in figure $3.3 .{ }^{19}$ Real debt falls by $1 \%$ in two years relative to the baseline and then rises back to the baseline again in about 8 years. Because monetary policy is neutral, there is no long-run effect on real debt. The result for monetary non-neutrality and a permanent effect on real debt will be examined in section 4 .

\section{The policy-rate effect on the probabil-} ities of a crisis start and a crisis The yellow line in figure 3.3 shows the resulting policyrate effect on $g_{t}$, the annual growth rate of (average annual) real debt. Because the real debt level first falls and then rises back to the baseline, real debt growth will first also fall below the baseline but then rise above the baseline. Importantly, because there is monetary neutrality and, after about 40 quarters, no policy-rate

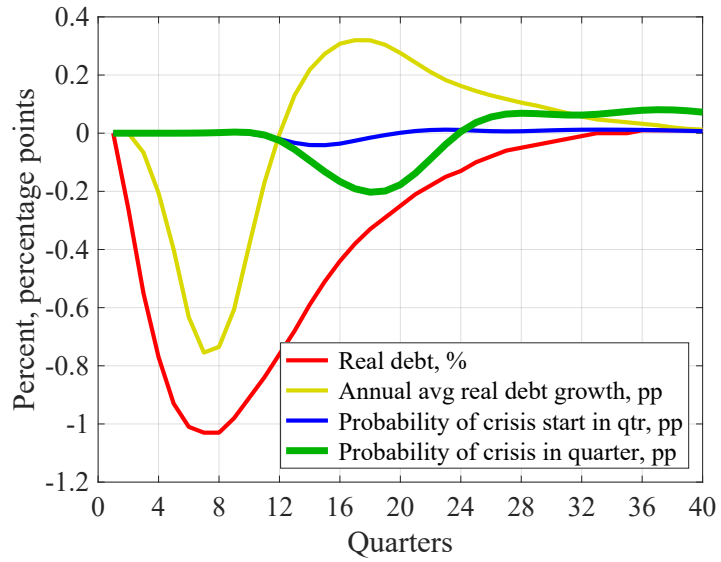

Figure 3.3: The policy-rate effect on real debt, annual average real debt growth, and the probabilities of a crisis start and a crisis

effect on real debt, there is no policy-rate effect on the cumulative growth rate.

The blue line in the figure shows the resulting policy-rate effect on the probability of a crisis start, $d q_{t} / d \bar{i}_{1}$, that follows from (3.1) and (3.2). Recall that real debt growth lagged two years is the main determinant of the probability of a crisis start. The probability of a crisis start falls below the baseline to a minimum of $-0.04 \mathrm{pp}$ in quarters 14 and 15 , about two years after the minimum of real debt growth rate in quarter 6. Furthermore, because real debt growth rises above the baseline after quarter 12 , the probability of a crisis will rise above the baseline after quarter 20 (barely visible in the figure).

The thick green line in the figure shows the policy-rate effect on the probability of a crisis, $d p_{t} / d \bar{i}_{1}$. Because it is close to the linear approximation mentioned above, it is approximately an 8-quarter moving sum of the policy-rate effect on the probability of a crisis start. It has a minimum of $-0.20 \mathrm{pp}$ in quarter 18 and then rises back to zero and turns positive from quarter 24 . It will fall to zero at about quarter $60 .^{20}$

\footnotetext{
19 The ST estimates refer to loans to both households and nonfinancial corporations, whereas the estimates in Sveriges Riksbank (2014a) refer to loans to households only. I assume that this difference does not affect the result.

20 Because real debt growth lagged 5 years has a relatively large coefficient coefficient in (3.2), the probability of a crisis is affected by real debt growth lagged up to 7 years.
} 
The logistic function is convex but close to linear for the relevant range of real debt growth rates (figure 4.3). Then the probability of a crisis start and of a crisis are approximately linear in real debt growth. It follows that monetary neutrality and no permanent effect on real debt in this case implies that the cumulative policy-rate effects of the probability of a crisis start and the probability of a crisis are approximately zero, $\sum_{t=1}^{60} d q_{t} / d \bar{i}_{1} \approx \sum_{t=1}^{60} d p_{t} / d \bar{i}_{1} \approx 0$. Thus, a higher policy rate reduces the probability of a crisis somewhat in $4-5$ years and increases it after about 6 years, but with an approximately zero cumulative effect over about 60 quarters.

We now have all the components of the marginal benefit from a lower probability of a crisis, (2.10). It is given by $\operatorname{MB}_{t}^{p}=(\Delta u)^{2}\left(-d p_{t} / d \bar{i}_{t}\right)=25\left(-d p_{t} / d \bar{i}_{t}\right)$, and is shown as the thin solid green line in figure 3.5. In this case, monetary neutrality implies that the cumulative marginal benefit from a lower probability of a crisis is approximately zero. As mentioned, section 4 examines the result for monetary non-neutrality and a permanent effect on real debt, for which the cumulative marginal benefit from a lower probability of a crisis will be positive.

The marginal benefit from a smaller magnitude of a crisis In order to find a numerical estimate of the marginal benefit from a smaller magnitude of a crisis, (2.11), we need to find an estimate of the policy-rate effect on the magnitude of a crisis. A possible channel is the effect of debt on the magnitude of a crisis combined with the policy-rate effect on debt.

The effect of debt on the magnitude of a crisis Regarding the effect of debt on the magnitude of a crisis, for the OECD countries Flodén (2014) finds that a lower household debt-toincome ratio in 2007 is associated with a lower increase in the unemployment rate during 2007-2012. More precisely, a $1 \mathrm{pp}$ lower debt-to-income ratio is associated with a $0.02 \mathrm{pp}$ smaller increase in the unemployment rate. Flodén's estimate is similar to other estimates. Given this, I will use Flodén's estimate as a representative benchmark.

Jordà et al. (2013, table 8) (JST for short), with a dataset for 14 advanced countries 1870-2008, report the effect on the GDP downturn in a financial recession of a 1 pp higher "excess credit." Here, excess credit denotes the yearly pp excess rate of change of aggregated bank loans relative to GDP in the preceding expansion phase (previous trough to peak, where excess is determined relative to the previous mean). The average effect on GDP over 5 years is -0.8 pp (the average of the coefficients in table 8). Assuming an Okun coefficient of 2, this means an average increase in the unemployment rate of $0.4 \mathrm{pp}$. Post-WWII, the average duration of an expansion phase is 9.46 
years in the sample. ${ }^{21} \mathrm{~A} 1 \mathrm{pp}$ higher excess credit over 9.46 years implies that the cumulative bankloans-to-GDP ratio is about $10 \%$ higher $\left(1.01^{9.46}-1=0.0987\right)$. This means that a 1 percent higher bank-loans-to-GDP ratio is associated with a $0.4 / 10=0.04 \mathrm{pp}$ larger unemployment increase. If the bank-loans-to-GDP ratio is about 100 percent, $1 \%$ is about 1 pp. ${ }^{22}$ Then, $1 p p$ higher bank loans is associated with about $0.04 \mathrm{pp}$ larger unemployment increase, about twice as large as Flodén's estimate. Krishnamurthy and Muir (2016, table 4), with a dataset for 14 countries 1869-2014, show that a 1 pp higher 3 -year growth in the credit-to-GDP ratio is associated with an (insignificant) 0.05 pp larger GDP decline from peak to trough in a financial crisis. With an Okun coefficient of 2, a $0.05 \mathrm{pp}$ decline in GDP is associated with a $0.025 \mathrm{pp}$ rise in the unemployment rate, an estimate similar to Flodén's.

\section{The policy-rate effect on debt to in- come and the magnitude of a crisis As}

discussed in section 1 , the policy-rate effect on debt to income may be positive rather than negative. The Sveriges Riksbank (2014a) estimate of the effect on the Swedish household debt-toincome ratio of a $1 \mathrm{pp}$ higher policy rate during quarters $1-4$ is negative and shown in figure 3.4.

It falls by $1.4 \mathrm{pp}$ in quarter 4 . This corresponds to a fall in debt to GDP of $0.8 \% .^{23}$ But this policy-rate effect on the debt-to-income ratio is

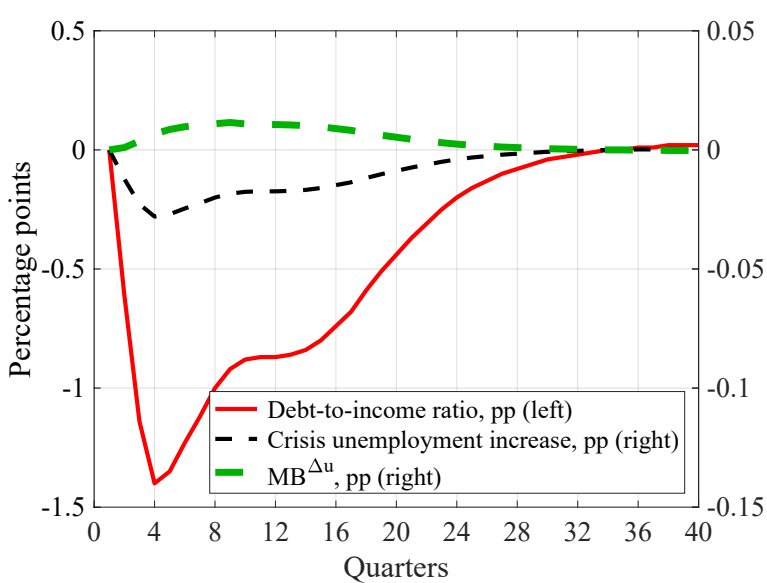

Figure 3.4: The policy-rate effect on the debtto-income ratio, the crisis magnitude, and the marginal benefit from a smaller crisis magnitude $\left(\mathrm{MB}^{\Delta \mathrm{u}}\right)$

too large to be consistent with the policy-rate effect on real debt in figure 3.3 and on the unemployment rate in figure 3.1. For an Okun coefficient of about 2, the policy-rate effect on GDP would be a fall by about $1 \%$ in quarter $6-8$, about the same as the fall in real debt in figure 3.3. This implies that the effect on the debt-to-GDP ratio would be close to zero. ${ }^{24}$

In order to stack the cards in favor of LAW, I will nevertheless use the Riksbank estimate as

\footnotetext{
${ }^{21}$ JST (table 3) reports an expansion-phase duration of 6.9 years for 30 observations of "Low excess credit" and a duration of 11.8 years for 32 observations of "High excess credit." The average, taking the numbers of observations into account, is then 9.46 years

22 According to BIS (2016b, table F2.3), for advanced economies, bank loans to the private non-financial sector were $83 \%$ of GDP in 2016Q1.

${ }_{23}$ Sveriges Riksbank (2014a) estimates the policy-rate effect on the debt-to-GDP ratio and converts that into the debt-to-(disposable)income ratio by assuming that income is proportional to GDP. The percent response of the debt-to-GDP ratio is then converted into percentage points by multiplying by an initial household debt-to-income ratio of 1.73 . Thus, a fall of 1.4 percentage points is a fall of $1.4 / 1.73=0.8$ percent.

24 This is consistent with the small or even positive policy-rate effect on GDP found in Alpanda and Zubairy (2014), Bauer and Granziera (2016), Gelain et al. (2015), Robstad (2014), and Svensson (2013a,b).
} 


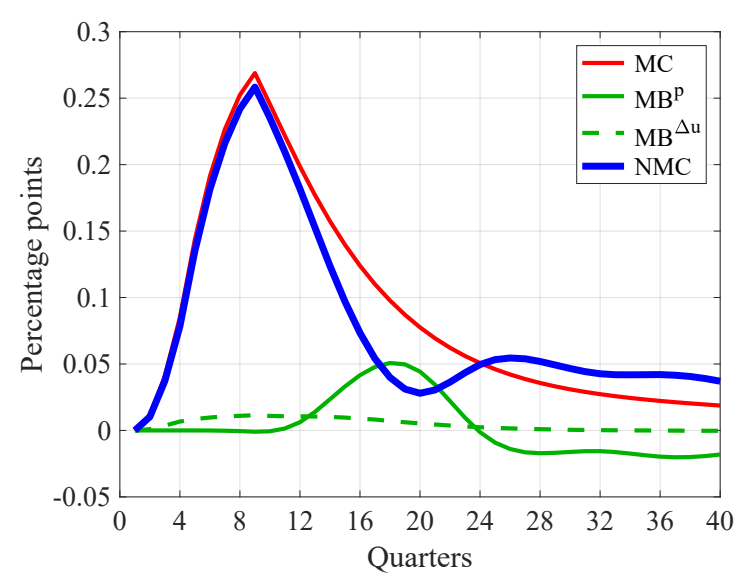

Figure 3.5: The marginal cost, marginal benefits from a lower probability and smaller magnitude of a crisis, and net marginal cost

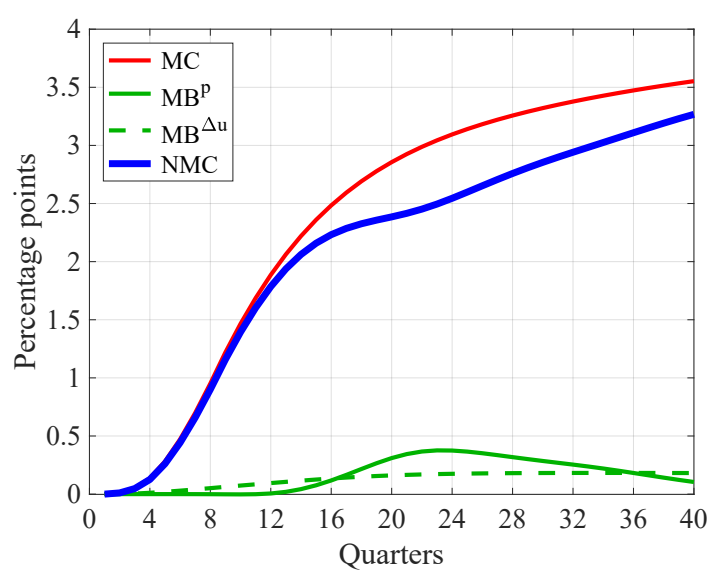

Figure 3.6: The cumulative marginal cost, marginal benefits from a lower probability and smaller magnitude of a crisis, and net marginal cost

a benchmark policy-rate effect on the debt-to-income ratio, even though it seems unrealistically large. Then the policy-rate effect on the magnitude of a crisis, $d \mathrm{E}_{1} \Delta u_{t} / d \bar{i}_{1}$, is simply 0.02 times the policy-rate effect on the debt-to-income ratio. It is shown as the dashed black line in figure 3.4 (measured along the right vertical axis). The maximum fall in the crisis unemployment increase is about $0.03 \mathrm{pp}$ for quarter 4 .

The resulting marginal benefit from a smaller magnitude of a crisis, (2.11), is then given by $\mathrm{MB}_{t}^{\Delta u}=2 p_{t} \Delta u\left(-d \mathrm{E}_{1} \Delta u_{t} / d \bar{i}_{1}\right)=10 p_{t}\left(-d \mathrm{E}_{1} \Delta u_{t} / d \bar{i}_{1}\right)$ and is shown as the thick dashed green line in figure 3.4 and the thin dashed green line in figure 3.5.

The net marginal cost We now have all the components of the net marginal cost. Figure 3.5 shows the marginal cost (thin solid red), (2.9); the marginal benefit from a lower probability of a crisis (thin solid green), (2.10); the marginal benefit from a smaller magnitude of crisis (thin dashed green), (2.11); and the net marginal cost (thick solid blue), (2.12), the difference between the red line and the sum of the solid and dashed green lines.

Figure 3.6 shows the corresponding (undiscounted) cumulative marginal cost, marginal benefits, and net marginal cost. (Because the main marginal benefit occurs later than the main marginal cost, not discounting stacks the cards in favor of LAW. $)^{25}$ The result that the cumulative marginal cost exceeds the cumulative marginal benefit by a substantial margin is clear.

Preliminarily, we also see an indication that an assumption of monetary non-neutrality and

${ }^{25}$ The undiscounted cumulative discounted net marginal cost is the limit of (2.12) for $\delta \rightarrow 1-$. 


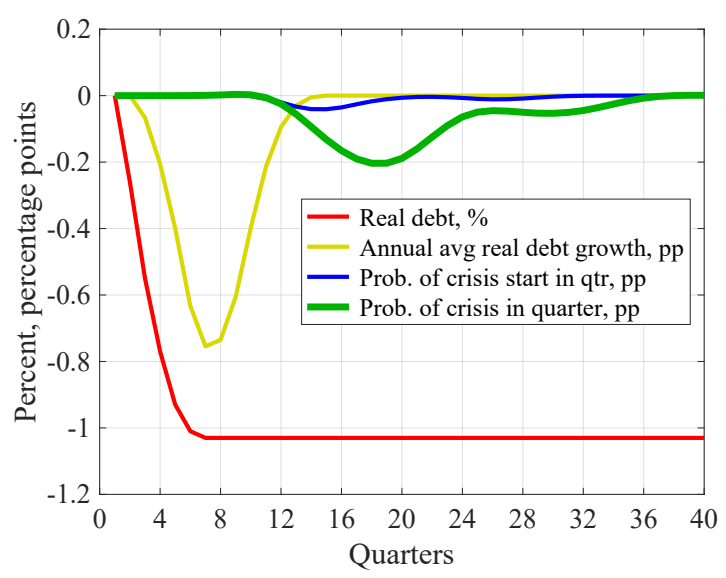

Figure 4.1: The policy-rate effect on real debt, annual average real debt growth, and the probabilities of a crisis start and a crisis; permanent effect on real debt

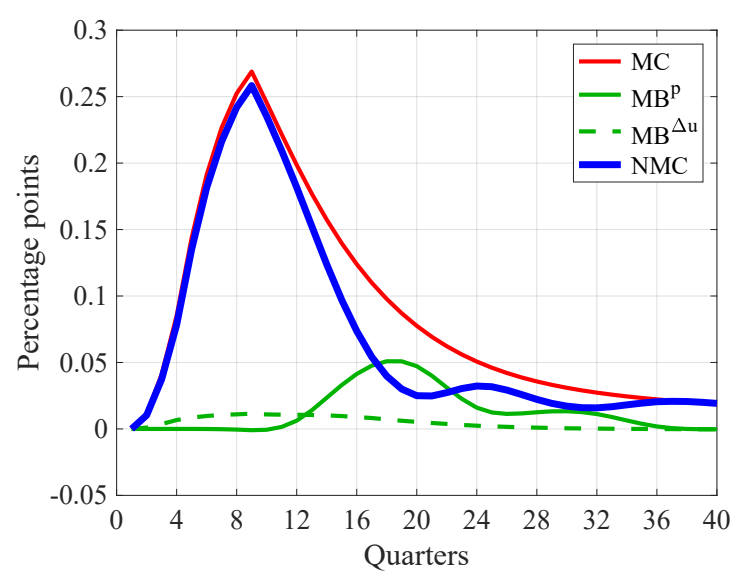

Figure 4.2: The marginal cost, marginal benefits from a lower probability and smaller magnitude of a crisis, and net marginal cost; permanent effect on real debt

a permanent effect on real debt would not change the result. Even if we disregard the negative marginal benefit and positive marginal cost after quarter 24 by just looking at the cumulative net marginal cost for quarter 24, the cumulative marginal cost still exceeds the marginal benefit by a substantial margin. The role of monetary neutrality and non-neutrality is further examined in section 4 .

\section{Robustness tests}

The benchmark estimates and assumptions in the previous sections have been chosen to be representative and realistic or, for the policy-rate effect on debt to income, biased in favor of LAW. In this section, I examine the robustness of the result to monetary non-neutrality and a permanent policy-rate effects on real debt; a smaller policy-rate effect on unemployment; a credit boom and a higher probability of a crisis start; a larger crisis magnitude; a longer crisis duration; inefficient macroprudential policy; larger policy-rate effects on the probability and magnitude of a crisis, including how many standard errors larger effects are required for break-even; and, finally, using debt to GDP (including using 5-year moving averages as in Jordà et al. (2016)) instead of real debt as a predictor of crises.

Non-neutral monetary policy and a permanent effect on real debt Assume that there is monetary non-neutrality in the form of a permanent effect on real debt. More precisely, assume 
that real debt permanently stays down at its maximum deviation from the baseline in figure 3.3 $(-1.03 \%)$ from quarter 8 onwards, as shown in figure 4.1 . Then there is a persistent, but not permanent, fall in the probability of a crisis. As shown in figure 4.2, the resulting marginal benefit is larger, more persistent, and never negative. Nevertheless, it is clear that this marginal benefit is not sufficient to prevent the cumulative marginal cost from exceeding the cumulative marginal benefit by a substantial margin. The result is robust to monetary non-neutrality and a permanent policy-rate effect on real debt.

A smaller policy-rate effect on the non-crisis unemployment rate A smaller policy-rate effect on the non-crisis unemployment rate will reduce the cumulative marginal cost and make it exceed the cumulative marginal benefit by less, or even fall short of the cumulative marginal benefit. Suppose that the policy-rate effect is only half the benchmark effect. That is, the policyrate effect is assumed to be substantially smaller than the one reported in IMF (2015, para. 40 and footnote 42) for its GIMF model and somewhat smaller than the impulse response of the U.S. unemployment rate estimated in Stock and Watson (2001, figure 1) (when adjusted to a similar cumulative policy-rate impulse as discussed in footnote 14). This would result in half the marginal cost in figure 3.5 and half the cumulative marginal cost in figure 3.6. Clearly, the cumulative marginal cost would still exceed the cumulative marginal benefit by a substantial margin.

Furthermore, if monetary non-neutrality and a permanent policy-rate effect on real debt is assumed as in figure 4.1, it is clear from figure 4.2 that half the benchmark policy-rate effect on the non-crisis unemployment rate would also in that case make the cumulative marginal cost exceed the cumulative marginal benefit by a substantial margin.

A credit boom and a higher probability of a crisis start How does a credit boom with an associated higher probability of a crisis start affect the net marginal cost of LAW? The conventional wisdom is certainly that this would be favorable to LAW, in the sense of reducing the net marginal cost of LAW, perhaps even make it. But this conventional wisdom is wrong in the current framework.

Figure 4.3 shows how the annual probability of a crisis start depends on annual steady real debt growth rate for the logit model (3.1) and (3.2) and the ST estimates. Point A corresponds to the benchmark annual real debt growth and annual probability of a crisis start of, respectively, $5 \%$ and $3.2 \%$. Assume a credit boom corresponding to point B, with annual real debt growth and 


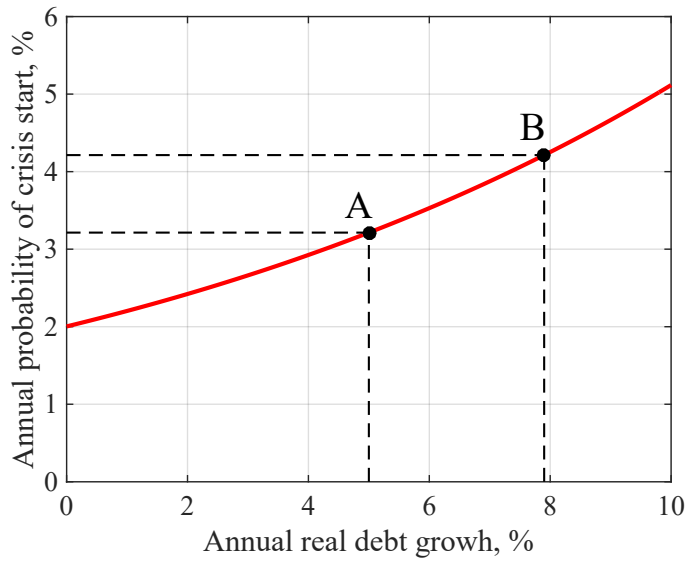

Figure 4.3: The annual probability of a crisis start as a function of steady annual real debt growth

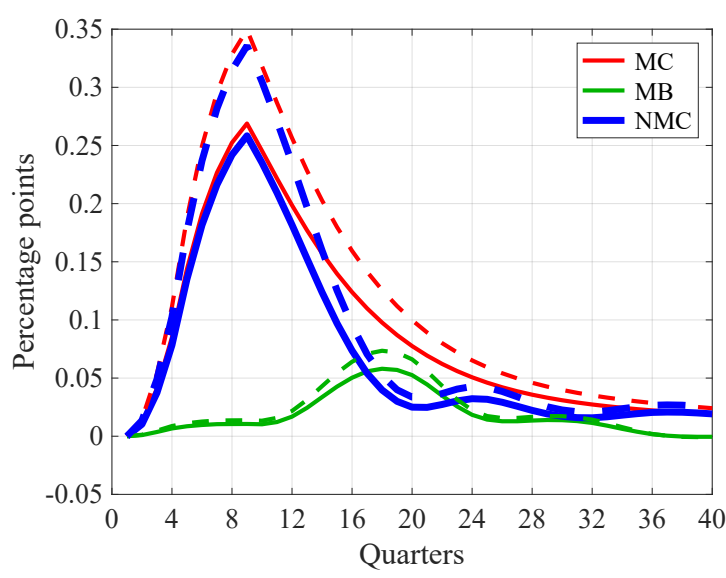

Figure 4.4: The effect of a higher probability of a crisis start (dashed lines) on the marginal cost, marginal benefit, and net marginal cost

probability of a crisis of, respectively, $7.9 \%$ and $4.2 \%$.

In order to stack the cards in favor of LAW, assume again monetary non-neutrality and a permanent policy-rate effect on real debt. In figure 4.4, the solid lines show the benchmark marginal cost, marginal benefit, and net marginal cost under this assumption, the same as in figure 4.2, except that only the sum (2.8) of the two marginal benefits is shown. The dashed lines show effect of the higher probability of a crisis start. The cumulative net marginal cost will be higher, not lower, so a credit boom with a higher probability of a crisis increases the marginal cost more than the marginal benefit. How can that be?

The higher probability of a crisis start, $q_{t}$, leads to a higher probability of a crisis, $p_{t}$. In figure 3.2 , the quarterly probability of a crisis start will be $4.2 / 4=1.05 \%$, and the probability of a crisis start will rise to $8.1 \%$ in quarter 9 and then fall back to $7.8 \%$.

Both the marginal cost (2.9) and the marginal benefit (2.11) are linear in the probability of a crisis, so the higher probability of a crisis then shifts up both in proportion. But because the marginal cost is higher than the marginal benefit from a smaller magnitude of a crisis, the net effect is an increase the net marginal cost. Furthermore, we see in figure 4.3 that the probability of a crisis start is slightly convex as a function of real debt growth. This means that, at point B, the probability of a crisis start and the probability of a crisis are somewhat more sensitive to real debt growth. Then the marginal benefit from a lower probability of a crisis, (2.10), will be somewhat higher. This shifts up the marginal benefit a bit. But we see that the net effect is still to shift up the net marginal cost and to make the cumulative net marginal cost higher. 


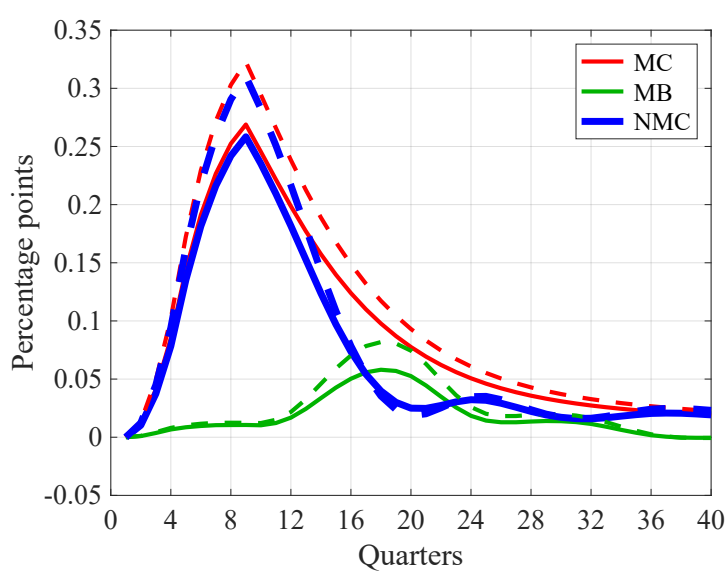

Figure 4.5: The effect of a larger crisis increase in the unemployment rate (dashed lines) on the marginal cost, marginal benefit, and net marginal cost

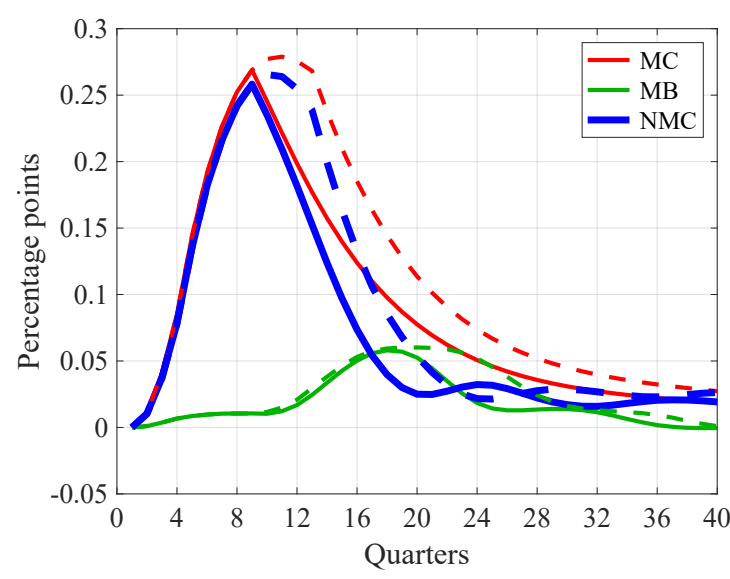

Figure 4.6: The effect of a longer crisis duration (dashed lines) on the marginal cost, marginal benefit, and net marginal cost

Thus, a credit boom and a corresponding higher probability of a crisis increases the cumulative net marginal cost of LAW, counter to the conventional wisdom. ${ }^{26}$

A larger crisis magnitude The conventional wisdom is certainly that a larger magnitude of a crisis would be favorable to LAW. Again the conventional wisdom is wrong in the present framework, except for extremely large crisis magnitudes.

A larger magnitude of a crisis is here represented by a larger crisis increase in the unemployment rate, $\Delta u$. The dashed lines in figure 4.5 show the marginal cost, marginal benefit, and net marginal cost for a $\Delta u$ equal to $6 \mathrm{pp}$ instead of the benchmark $5 \mathrm{pp}$. Again, I assume monetary nonneutrality and a permanent policy-rate effect on real debt, in order to stack the cards in favor of LAW. But as we see, the net marginal cost instead increases, except around quarters 19 and 20, and the cumulative net marginal cost increases, counter to the conventional wisdom.

To understand this, note that the marginal cost (2.9) and the marginal benefit from a smaller magnitude of a crisis (2.11) are both linear in $\Delta u$ and shift up in proportion. But because the marginal cost is larger, the net effect is to increase the net marginal cost. Furthermore, we see from (2.10) that the marginal benefit from a lower probability of a crisis is quadratic in $\Delta u$. This shifts up the marginal benefit more than in proportion and reduces the net marginal cost. But because the marginal benefit from a lower probability of a crisis is relatively small, the net effect of the shifts in the marginal cost and benefits is an increase in cumulative marginal cost.

26 Discussions with Helge Berger were helpful for the interpretation of this result. 
However, because the marginal cost is linear but the marginal benefit from lower probability of a crisis is quadratic in $\Delta u$, we realize that a sufficiently large $\Delta u$ can increase the marginal benefit from a lower probability of a crisis so much as to achieve break-even, with the cumulative net marginal cost of LAW equal to zero. But this requires an extremely large $\Delta u$ of $32 \mathrm{pp} .^{27}$

A longer crisis duration The conventional wisdom is certainly that a longer duration of a crisis would favor LAW. But instead the cumulative net marginal cost increases, counter to the conventional wisdom.

In figure 4.6, the dashed lines show the marginal cost, marginal benefit, and net marginal cost for a longer crisis duration of $n=12$ quarters instead of the benchmark 8 quarters. In figure 3.2, a longer duration of 12 quarters means that the probability of crisis rises further to $9.2 \%$ in quarter 13 and then falls back to $8.8 \%$ rather than $6 \%$. As a result of the longer duration and higher probability of a crisis, both the marginal cost and the marginal benefit are extended to the right and shifted up. Because the marginal cost is initially higher than the marginal benefit, this will increase the net marginal cost, except around quarter 24, where the marginal benefit increases slightly more than the marginal cost. The result is that the cumulative net marginal cost increases.

Inefficient macroprudential policy The conventional wisdom is certainly that LAW is more appropriate in a situation with less effective macroprudential policy. Such a situation would likely imply a more vulnerable economy, with higher probability, larger magnitude, or longer duration of crises. But above we have seen that for each of these changes, the costs exceed the benefits by an even larger margin. Thus, this conventional wisdom is wrong here.

A larger policy-rate effect on the probability of crisis As mentioned, the benchmark policy-rate effect on the probability of a crisis is constructed from the Sveriges Riksbank (2014a) estimate of the policy-rate effect on household debt combined with the ST estimate of the effect of debt on the probability of a crisis start. For monetary monetary neutrality and no permanent policy-rate effect on real debt, the cumulative marginal benefit from a lower probability of a crisis is approximately zero. Then a larger policy-rate effect on debt or a larger effect of debt on the probability of a crisis would still have an approximately zero effect on the cumulative net marginal

\footnotetext{
27 Because the policy-rate effect on the non-crisis unemployment rate and the marginal cost are still positive at quarter 40, for a precise result the horizon needs to be extended further; 60 quarters is sufficient. Beyond quarter 40, because there is no data on the Riksbank policy-rate effect on the unemployment rate, it is assumed to fall exponentially at a rate 3 times faster than the rate from quarter 32 to 40 (so as to not exaggerate the marginal cost beyond quarter 40 ). Then $\Delta u=32 \mathrm{pp}$ makes the cumulative net marginal cost at quarter 60 close to zero.
} 
cost.

In order to stack the cards in favor of LAW, let me then again assume monetary non-neutrality and a permanent policy-rate effect on real debt. Then the cumulative marginal benefit from a lower probability of a crisis is positive, as shown in figure 4.4, and a larger policy-rate effect on the probability of a crisis would increase the cumulative marginal benefit and reduce the cumulative net marginal cost.

To achieve break-even, that is, a cumulative net marginal cost equal to zero, the policy-rate effect on the probability of a crisis start, $d q_{t} / d \bar{i}_{1}$, then needs to be about 6.4 times as large as the benchmark.

A larger policy-rate effect on the probability of a crisis start can be achieved through a larger policy-rate effect on debt or a larger effect of debt on the probability of a crisis start, or both. Assume that it is achieved through a larger policy-rate effect on debt. For break-even, the policyrate effect on real debt then needs to be 6.4 times as large as the Riksbank estimate (the red line in figure 3.3). That is, real debt needs to fall by about $6.4 \%$ in quarter 8 instead of $1 \%$. With a standard error of about $1 \mathrm{pp}$, this is an effect about 5.4 standard errors larger than the Riksbank estimate. Clearly, the margin to break-even is large. ${ }^{28}$

If break-even is achieved through a larger effect of debt on the probability of a crisis start, the effect needs to be about 6.4 times as large as the ST estimate. This implies an effect that is about 15 standard errors larger than the ST estimate. Clearly, the margin to break-even is quite large. ${ }^{29}$

For some LAW to be optimal, the policy-rate effect on the probability of a crisis needs to be even larger. For a permanent effect on real debt, for $\Delta \bar{i}_{1}=0.5$ pp to be (approximately) optimal an effect 10 times as large as the benchmark is required.

A larger policy-rate effect on the magnitude of a crisis The benchmark policy-rate effect on the magnitude of a crisis uses the Sveriges Riksbank (2014a) estimate of the policy-rate effect on household debt to income and combines it with the Flodén (2014) estimate of the effect on debt to income on the magnitude of a crisis. A larger (negative) policy rate effect on the magnitude of a crisis would increase the marginal benefit from a smaller magnitude and reduce the cumulative net marginal cost. But just to achieve break-even requires a policy-rate effect on the magnitude of

\footnotetext{
${ }^{28}$ Sveriges Riksbank (2014a, figure A20) reports uncertainty intervals around the point estimate of the policy-rate effect on real debt. The $12.5+75=87.5$ th percentile exceeds the point estimate at quarter 8 by 1 pp, which can then be taken to be an approximate (upper bound of the) standard error.

29 The largest and most significant coefficient is 7.138, with a standard error of 2.631 (ST (table 3, specification 6 )). The required effect needs to be 6.43 times as large. Then the coefficient needs to increase by $(6.43-1) \cdot 7.138 / 2.631=$ 14.7 standard errors.
} 
a crisis that is about 20 times as large as the benchmark effect.

The larger policy-rate effect on the magnitude of a crisis start can be achieved through a larger policy-rate effect on debt to income or a larger effect of debt to income on the magnitude of a crisis, or both. If break-even is achieved through a larger policy-rate effect on debt to income, the effect needs to be about 20 times as large as the Riksbank estimate (the solid red line in figure 3.4). The average benchmark effect for quarters $4-10$ is a fall of $1.13 \mathrm{pp}$. For break-even, debt to income then needs to fall by about $21 \mathrm{pp}$ for quarters $4-10$. This is an effect that is about 13 standard errors larger than the benchmark effect. Clearly, the margin to break-even is quite large. ${ }^{30}$

If break-even is achieved through a larger effect of debt to income on the magnitude of a crisis, it needs to be about 18 times as large as the Flodén (2014, table 4, column 1) estimate. This implies an effect that is about 43 standard errors larger than the Flodén estimate and about 12 standard errors larger than the estimate that follows from JST. Clearly, the margin to break-even is quite large. ${ }^{31}$

For some LAW to be optimal, the policy-rate effect on the magnitude of a a crisis needs to be even larger. For a permanent effect on real debt, for $\Delta \bar{i}_{1}=0.5$ pp to be (approximately) optimal, an effect 30 times as large as the benchmark is required.

Debt to GDP instead of real debt and 5-year moving averages One might think that using debt-to-GDP instead of real debt as a predictor of crisis might lead to a different result. But this is not so.

ST (table 4, specification 9) report a specification where the annual growth of real debt in the logistic function is replaced by the annual growth of debt to income. Jordà et al. (2016) use a 5-year moving average of the annual growth of debt to income. Using the debt-to-GDP ratio instead of

\footnotetext{
${ }^{30}$ Sveriges Riksbank (2014a, figure A22) reports uncertainty intervals around the point estimate of the policy-rate effect on debt to income. The $12.5+75=87.5$ th percentile exceeds the point estimates on average about $1.6 \mathrm{pp}$ around quarters $4-10$. This can be taken as an approximate (upper bound of the) standard error. The effect then needs to increase by $(20-1) \cdot 1.13 / 1.6=13.4$ standard errors.

31 The benchmark estimate used is 0.02 and the required effect is 0.406 . Flodén's estimate of the effect is actually 0.0230 , with a standard error of 0.00897 . (Flodén (2014, table 4, column 1) does not report the standard error and reports the point estimate with only two decimals, but the data and programs to replicate his estimate and extract the standard error are available at http://martinfloden.net/files/hhdebt_replicate.zip.) This means that the required effect is $0.41 / 0.023=17.8$ as large as Flodén's estimate, $(0.41-0.023) / 0.00897=43.1$ standard errors larger.

The estimated effect of credit to GDP on the unemployment increase that follows from JST (table 8) is 0.04, as explained in section 3. The average standard error over years $1-5$ for the effect of excess credit on GDP is 0.625 (in the row "Excess credit $\times$ financial recession" in table 8$)$. With an Okun coefficient of 2, the average standard error for the effect of excess credit on the crisis increase in the unemployment rate can be considered to be $0.625 / 2=0.313$. Because $1 \mathrm{pp}$ excess credit per year corresponds to about a $10 \mathrm{pp}$ higher credit-to-GDP ratio, the standard error for the effect of credit to GDP on the crisis increase in unemployment is $0.313 / 10=0.0313$. This means that the required effect for break-even is approximately $(0.41-0.04) / 0.0313=11.8$ standard errors larger than the estimate that follows from JST.
} 
real debt or using 5-year moving averages of it instead of 5 lags lead to a policy-rate effect on the probability of a crisis and a marginal benefit of LAW similar to the ones in, respectively, figures 3.3 and 3.5. Thus, the cumulative marginal cost still exceeds the cumulative marginal benefit by a substantial margin.

ST (table 7, specification 22) contains a logit regression of the annual probability of a crisis start, where the log of the debt-to-GDP ratio is added as an explanatory variable in the logistic function (3.1) and (3.2). Svensson (2016a, appendix D) shows that adding this explanatory variable has a negligible effect on the probability of a crisis start and the marginal benefit in, respectively, figures 3.3 and 3.5, and thus does not affect the result.

\section{Conclusions and qualifications}

A simple, transparent, and robust framework for a cost-benefit analysis of LAW has been presented. The costs of LAW are not only a weaker economy if no crisis occurs. There is also a second cost, namely, for a given magnitude of a crisis a weaker economy if a crisis occurs. The crisis loss and the cost of a crisis (the crisis loss less the non-crisis loss) will for a given magnitude of a crisis be higher with LAW, something that has been overlooked by the previous literature. The possible benefits of LAW include a lower probability and smaller magnitude of a crisis. For existing representative empirical estimates and reasonable assumptions, the result is that the costs of LAW exceed the benefits by a substantial margin. The reason is that the empirical policy-rate effects on the probability and magnitude of a crisis are far too small to make the benefits of LAW match the cost.

The result is robust to monetary non-neutrality and a permanent policy-rate effect on real debt; a smaller policy-rate effect on unemployment; a credit boom with a higher probability of a crisis; a larger crisis magnitude; a longer crisis duration; larger policy-rate effects on the probability and duration of a crisis; and using debt to GDP, including 5-year moving averages, instead of real debt as a predictor of crises. In particular, to overturn the result the policy-rate effects on the probability and magnitude of a crisis need to be more than 5-40 standard errors larger than the point estimates, in spite of some of the estimates having large standard errors relative to the point estimates. This indicates that the result is quite robust.

Given the simplicity and transparency of the framework and its dependence on only a few assumptions and empirical estimates of the policy-rate effects on unemployment and the probability 
and magnitude of a crisis, it is easy to redo the analysis with alternative assumptions or new alternative or better empirical estimates. This way the robustness of the result can be further examined.

Some previous or recent papers (including Ajello et al. (2016), FR, and GKS) have found that some LAW is optimal. But, as shown in Svensson (2016a, 2017b) and discussed in section 1, this is due to different but less realistic assumptions about the costs of LAW, namely that either the crisis loss level or the cost of a crisis is independent of LAW. Furthermore, the optimal LAW and net gain is then too small to have any practical relevance, corresponding to only a few basis points higher policy rate or a few basis points lower probability of a crisis.

A possible objection to the framework and result of this paper is that LAW need not be an unanticipated temporary increase in the policy rate as represented here. Instead it could instead be a different policy regime, where the policy rate systematically responds to indicators of financial instability for financial-stability purposes and where this systematic response is incorporated into private-sector expectations and changes private-sector behavior.

However, first, if such a systematic LAW is a good and robust policy, it should be beneficial also when it is done as a temporary increase in the policy rate, and the policy should pass the costbenefit test conducted in this paper. Furthermore, it is easy to see considerable conceptual and practical difficulties with a systematic policy of LAW, and after its introduction it could realistically take several years, if not forever, for it to be credible and affect expectations.

Second, a temporary policy-rate increase can be seen in the light of standard so-called "calculus of variations," the generalization of calculus used in dynamic optimization theory. According to this, the optimality of any policy can be checked (and the first-order conditions for optimality be derived) from the effects on the (intertemporal) loss of any deviation from the policy, including the temporary policy rate increase used in this framework. The optimality condition is that any policy deviation must not reduce the loss. If the loss increases for a particular deviation and falls for the opposite deviation, this indicates that the optimal policy lies in the latter direction. In this framework, the loss increases for a higher and falls for a lower policy-rate, indicating that the optimal policy lies in the latter direction. (However, the optimal leaning with the wind is too small to have any practical relevance.)

Third, it may of course be of interest to examine the consequences of a systematic policy of LAW and how it might affect expectations. But any such examination of a systematic policy requires a complicated model with many assumptions and complicated parameter estimation. The results 
will be heavily model-dependent and not very robust. It is of course always possible to construct a model in which some LAW is optimal; the question is how reasonable and realistic the model is. The simplicity and transparency of the framework here and, in particular, its dependence on only a few assumptions and estimates may in many or most cases imply a more reliable and robust examination of the costs and benefits of LAW. In any case, the substantial margin by which the costs of LAW exceed the benefits for the benchmark estimates in this framework and the robustness tests passed arguably make it rather unlikely that the outcome for a systematic policy of LAW would be different in a reasonable and realistic model.

A second possible objection is that one might expect LAW to be more appropriate and effective in a situation with a credit boom and an elevated probability of a financial crisis. However, this is precisely the situation considered in one of the robustness tests in section 4, namely, a higher growth of debt with a higher probability of a crisis that is more sensitive to debt growth and the policy rate. As shown, in such a situation the margin of costs over benefits is even larger.

A third possible and somewhat related objection is the conventional wisdom that LAW may be appropriate as a last resort, that is, in a situation with less effective (if not non-existing) macroprudential policy. Although there is no explicit macroprudential policy in the framework here, we would expect less effective macroprudential policy to result in a more vulnerable economy, with a higher probability, a larger magnitude, or a longer duration of crises. But the robustness tests for these three alternatives show that, for each of them, the costs of LAW increase more than the benefits, making the costs exceed the benefits by an even larger margin. Thus, this conventional wisdom is wrong here, and the result supports Williams (2015) conclusion that "monetary policy is poorly suited for dealing with financial stability concerns, even as a last resort" (italics added).

A fourth possible objection, suggested by $\mathrm{AD}$, is that the so-called risk-taking channel, according to which a low policy rate increases the risk-taking of financial institutions, could increase the policy-rate effect on the probability or magnitude of crisis. But, first, more risk-taking need not imply "excessive" risk-taking. Second, to the extent that any risk-taking channel works through increased debt growth, its predictive power for crises may be picked up by the reduce-form results of ST. Third, I am not aware of any empirical results that the risk-taking channel is economically significant. In a thorough and comprehensive study, Dell'Ariccia et al. (2017) find that the federal funds rate has a statistically significant effect on the loan risk ranking of U.S. banks, but the effect is economically insignificant. An increase of $1 \mathrm{pp}$ of the federal funds rate reduces the loan-risk measure by only about $1 / 16$ of its standard deviation, implying that loan risk is mainly determined 
by other factors. ${ }^{32}$

The main reason why the costs of LAW exceed the benefits by a substantial margin is the small empirical policy-rate effects on the probability and magnitude of a crisis. Stein (2013) has suggested that monetary policy has one important advantage relative to supervision and regulation - namely that it "gets in all of the cracks." However, according to the numbers presented in this paper, a sizable policy-rate increase increase will barely cover the bottom of these cracks, much less fill them. Instead, so far, a general policy conclusion seems to be that, in order to substantially reduce the probability and magnitude of a financial crises there is no choice but to rely on other policies than monetary policy, such as micro- and macroprudential, housing, or fiscal policies, depending on the nature of the problem. For example, Dagher et al. (2016) show that around 20\% bank capital relative to risk-weighted assets might have been enough to avoid about $80 \%$ of the historical banking crises in the OECD countries since 1970. Thus, more but still relatively modest capital may lead to a much larger fall in the probability and frequency of crises than the small reductions that monetary policy so far seems able to achieve.

However, one should obviously never say never. One cannot of course exclude that newer and better empirical estimates - including data from emerging markets and not only advanced economies - or new channels for the policy-rate effects on the probability and magnitude of crises could overturn the result here about the costs and benefits of LAW.

\section{References}

Adrian, Tobias, and Fernando Duarte (2016), "Financial Vulnerability and Monetary Policy," Staff Report No. 804, December 2016, Federal Reserve Bank of New York.

Adrian, Tobias, and Nellie Liang (2017), "Monetary Policy, Financial Conditions, and Financial Stability," International Journal of Central Banking, forthcoming.

Ajello, Andrea, Thomas Laubach, David Lopez-Salido, and Taisuke Nakata (2016), "Financial Stability and Optimal Interest-Rate Policy," Finance and Economics Discussion Series 2016-067, Federal Reserve Board.

Allen, Franklin, Charles Bean, and José De Gregorio (2016), "Independent Review of BIS Research: Final Report," Report, www.bis.org.

\footnotetext{
32 The standard deviation of the loan risk rating is 0.847 (table 1 ). The federal-funds-rate effect on the loan risk rating is -0.052 (table 4 , column 4 ), corresponding to $0.052 / 0.847=6.1 \%$ of the standard deviation.
} 
Alpanda, Sami, and Sarah Zubairy (2014), "Addressing Household Indebtedness: Monetary, Fiscal or Macroprudential Policy?" Working Paper 2014-58, Bank of Canada.

Bauer, Gregory H., and Eleonora Granziera (2016), "Monetary Policy, Private Debt and Financial Stability Risks," Working Paper.

BIS (2014), 84th Annual Report, Bank for International Settlements.

BIS (2016a), 86th Annual Report, Bank for International Settlements.

BIS (2016b), "Statistics Explorer," Bank for International Settlements, stats.bis.org/statx/.

Bordo, Michael D., and Christopher M. Meissner (2016), "Fiscal and Financial Crises," NBER Working Paper No. 22059, National Bureau of Economic Research.

Borio, Claudio, and Mathias Drehmann (2009), "Assessing the Risk of Banking Crises - Revisited," BIS Quarterly Review, 29-46.

Dagher, Jihad, Giovanni Dell'Ariccia, Luc Laeven, Lev Ratnovski, and Hui Tong (2016), "Benefits and Costs of Bank Capital," Staff Discussion Note SDN/16/04, International Monetary Fund.

Dell'Ariccia, Giovanni, Luc Laeven, and Gustavo Suarez (2017), "Bank Leverage and Monetary Policy's Risk-Taking Channel: Evidence from the United States," Journal of Finance, forthcoming.

Diaz Kalan, Federico, Stefan Laséen, David Vestin, and Aleksandra Zdzienicka (2015), "Leaning Against the Wind: A Note on Costs and Benefits," Working Paper, International Monetary Fund, in progess.

Drehmann, Mathias, Claudio Borio, and Kostas Tsatsoranis (2012), "Characterising the Financial Cycle: Don't Lose Sight of the Medium Term," BIS Working Paper No. 380, Bank for International Settlements.

Ekholm, Karolina (2013), "Stabiliseringspolitiken och arbetslösheten (Stabilization Policy and Unemployment, in Swedish)," Presentation at LO, Stockholm, June 19, 2013, Sveriges Riksbank, available at www.lo.se.

Filardo, Andrew, and Phurichai Rungcharoenkitkul (2016), "Quantitative Case for LeaningAgainst-the-Wind," BIS Working Paper No. 594, Bank for International Settlements.

Flodén, Martin (2014), "Did Household Debt Matter in the Great Recession?" Supplement to blog post on Ekonomistas.se, www.martinfloden.se. 
Gelain, Paolo, Kevin J. Lansing, and Gisle J. Natvik (2015), "Leaning Against the Credit Cycle," Working Paper 04-2015, Norges Bank.

Gourinchas, Pierre-Olivier, and Maurice Obstfeld (2012), "Stories of the Twentieth Century for the Twenty-First," American Economic Journal: Macroeconomics, 226-265.

Gourio, François, Anil K. Kashyap, and Jae Sim (2016), "The Tradeoffs in Leaning Against the Wind," Paper presented at the IMF Annual Research Conference, November 2016.

IMF (2015), "Monetary Policy and Financial Stability,” Staff Report, International Monetary Fund.

Jordà, Òscar, Moritz Schularick, and Alan M. Taylor (2013), "When Credit Bites Back," Journal of Money, Credit and Banking, 45, Supplement(2), 3-28.

Jordà, Òscar, Moritz Schularick, and Alan M. Taylor (2016), "The Great Mortgaging: Housing Finance, Crises and Business Cycles," Economic Policy, 107-152.

Juselius, Mikael, Claudio Borio, Piti Disyatat, and Mathias Drehmann (2016), "Monetary Policy, the Financial Cycle, and Ultra-Low Interest Rates," BIS Working Paper No. 569, Bank for International Settlements.

Korinek, Anton, and Alp Simsek (2016), "Liquidity Trap and Excessive Leverage," American Economic Review, 106(3), 699-738.

Krishnamurthy, Arvind, and Tyler Muir (2016), "How Credit Cycles across a Financial Crises," Working Paper, people.stanford.edu/akris/.

Laeven, Luc, and Fabián Valencia (2012), "Systemic Banking Crises Data: An Update," Working Paper WP/12/163, International Monetary Fund.

Mian, Atif R., Amir Sufi, and Emil Verner (2016), "Household Debt and Business Cycles Worldwide," Working Paper, www.papers.ssrn.com.

Olsen, Øystein (2015), "Integrating Financial Stability and Monetary Policy Analysis," Speech at the London School of Economics, London, April 27, 2015, Norges Bank.

Robstad, Ørjan (2014), "House Prices, Credit and the Effect of Monetary Policy in Norway: Evidence from Structural VAR Models," Working paper 05-2015, Norges Bank.

Schularick, Moritz, and Alan M. Taylor (2012), "Credit Booms Gone Bust: Monetary Policy, Leverage Cycles, and Financial Crises, 1870-2008," American Economic Review, 102, 1029-1061. 
Stein, Jeremy C. (2013), "Overheating in Credit Markets: Origins, Measurement, and Policy Response," Speech on February 7, 2013, Federal Reserve Board.

Stock, James H., and Mark W. Watson (2001), "Vector Autoregressions," Journal of Economic Perspectives, 15(4), 101-115.

Sutherland, Douglas, Peter Hoeller, Rossana Merola, and Volker Zieman (2012), "Debt and Macroeconomic Stability," OECD Economics Department Working Paper No. 1003, OECD.

Svensson, Lars E.O. (2013a), "Leaning Against the Wind' Leads to a Higher (Not Lower) Household Debt-to-GDP Ratio," Working Paper, Stockholm School of Economics, www.larseosvensson.se.

Svensson, Lars E.O. (2013b), "The Riksbank Is Wrong about the Debt: Higher Policy Rates Increase Rather than Decrease the Household-Debt Ratio," Vox: CEPR's Policy Portal, September 4, www.voxeu.org.

Svensson, Lars E.O. (2014), "Inflation Targeting and 'Leaning Against the Wind'," International Journal of Central Banking, 10(2), 103-114.

Svensson, Lars E.O. (2015), "Inflation Targeting and Leaning Against the Wind," in Fourteen Years of Inflation Targeting in South Africa and the Challenge of a Changing Mandate: South African Reserve Bank Conference Proceedings 2014, South African Reserve Bank, pages 19-36, available at www.larseosvensson.se.

Svensson, Lars E.O. (2016a), "Cost-Benefit Analysis of Leaning Against the Wind: Are Costs Larger Also with Less Effective Macroprudential Policy?" IMF Working Paper WP/16/03, International Monetary Fund.

Svensson, Lars E.O. (2016b), "Discussion (revised) of Filardo and Rungcharoenkitkul, Quantitative Case for Leaning-Against-the-Wind," Research Forum on Macro-Finance, Centre for Central Banking Studies, Bank of England, May 26-27, Stockholm School of Economics, www.larseosvensson.se.

Svensson, Lars E.O. (2017a), "How Robust Is the Result That the Cost of 'Leaning Against the Wind' Exceeds the Benefit? Response to Adrian and Liang," Working Paper (also available as CEPR Discussion Paper DP11744), Stockholm School of Economics, www.larseosvensson.se.

Svensson, Lars E.O. (2017b), "Leaning Against the Wind: The Role of Assumptions About the Cost of a Crisis," Working Paper, Stockholm School of Economics, www.larseosvensson.se. 
Sveriges Riksbank (2013), "Financial Imbalances in the Monetary Policy Assessment," Monetary Policy Report July 2013.

Sveriges Riksbank (2014a), "The Effects on Monetary Policy on Household Debt," Monetary Policy Report February 2014.

Sveriges Riksbank (2014b), Monetary Policy Report February 2014, Sveriges Riksbank.

Williams, John C. (2015), "Macroprudential Policy in a Microprudential World," Speech in Singapore, May 28, 2015, Federal Reserve Bank of San Francisco. 


\section{Appendix}

\section{A The optimal unemployment rate and the indirect loss function}

Assume a quadratic loss function of inflation and unemployment,

$$
L^{*}\left(\pi_{t}, u_{t}\right) \equiv \pi_{t}^{2}+\lambda\left(u_{t}-\bar{u}\right)^{2},
$$

where $\pi_{t}$ denotes the gap between the inflation rate in quarter $t$ and and a fixed inflation target, and $u_{t}-\bar{u}$ denotes the gap between the unemployment rate $u_{t}$ in quarter $t$ and the long-run sustainable unemployment rate $\bar{u}$, and $\lambda>0$ denotes the constant weight on unemployment-gap stabilization relative to inflation-gap stabilization. With a positive weight on both inflation and unemployment stabilization, this loss function represents flexible inflation targeting.

Assume a simple Phillips curve,

$$
\pi_{t}=-\kappa\left(u_{t}-\bar{u}\right)+z_{t},
$$

where $z_{t}$ is an exogenous stochastic process with a zero unconditional mean. It represents cost-push shocks that cause a tradeoff between stabilizing inflation at the inflation target and unemployment rate at its long-run sustainable rate.

Using (A.2) to substitue for $\pi_{t}$ in (A.1) results in

$$
L^{*}\left[-\kappa\left(u_{t}-\bar{u}\right)+z_{t}, u_{t}\right]=\left[-\kappa\left(u_{t}-\bar{u}\right)+z_{t}\right]^{2}+\lambda\left(u_{t}-\bar{u}\right)^{2} .
$$

Choosing $u_{t}$ to minimize (A.3) gives the optimal unemployment rate under flexible inflation targeting, $u_{t}^{*}$, which satisfies

$$
u_{t}^{*} \equiv \bar{u}+\frac{\kappa z_{t}}{\lambda+\kappa^{2}}
$$

Using (A.4) to replace $z_{t}$ in (A.3) results, after some algebra, in the indirect loss function $L^{0}\left(u_{t}, u_{t}^{*}\right)$, which satisfies

$$
L^{0}\left(u_{t}, u_{t}^{*}\right) \equiv L_{t}^{*}\left(-\kappa\left(u_{t}-\bar{u}\right)+\frac{\lambda+\kappa^{2}}{\kappa} u_{t}^{*}, u_{t}\right)=\left(\lambda+\kappa^{2}\right) L\left(u_{t}-u_{t}^{*}\right)+\frac{\lambda\left(\lambda+\kappa^{2}\right)}{\kappa^{2}}\left(u_{t}^{*}-\bar{u}\right)^{2},
$$

where the simple loss function $L\left(u_{t}-u_{t}^{*}\right)$ is given by

$$
L\left(u_{t}-u_{t}^{*}\right) \equiv\left(u_{t}-u_{t}^{*}\right)^{2} .
$$


Clearly, choosing $u_{t}$ to minimize the simple loss function (A.6) is equivalent to choosing $u_{t}$ to minimize (A.5) and thus to choosing $u_{t}$ to minimize (A.1) subject to (A.2).

The optimal unemployment rate under flexible inflation targeting, $u_{t}^{*}$, is called the benchmark unemployment rate. The deviation between the actual unemployment rate and the benchmark unemployment rate, $u_{t}-u_{t}^{*}$, will be called the unemployment deviation.

\section{B A cost-push shock correlated with the crisis}

A crisis is considered to be a negative demand shock that, net of possible conventional and unconventional policy actions during the crisis to reduce its costs, increases the unemployment deviation, $\tilde{u}_{t} \equiv u_{t}-u_{t}^{*}$, by the amount $\Delta u_{t}>0$. The demand shock and the cost-push shock, $z_{t}$, are assumed to be independent. Then, by (A.4), $u_{t}^{*}$, the benchmark unemployment rate, is independent of a crisis and $\Delta u_{t}$ is the crisis increase in the unemployment rate, $u_{t}$.

By (A.5)-(A.6), we can write the quarter-1 expectation of the quarter- $t$ loss increase in a crisis, the cost of a crisis, as

$$
\begin{aligned}
\mathrm{E}_{1}\left[L^{0}\left(u_{t}, u_{t}^{*}\right) \mid \mathrm{c}\right]-\mathrm{E}_{1}\left[L^{0}\left(u_{t}, u_{t}^{*}\right) \mid \mathrm{n}\right]= & \left(\lambda+\kappa^{2}\right)\left\{\mathrm{E}_{1}\left[\left(u_{t}-u_{t}^{*}\right)^{2} \mid \mathrm{c}\right]-\mathrm{E}_{1}\left[\left(u_{t}-u_{t}^{*}\right)^{2} \mid \mathrm{n}\right\}\right. \\
& +\frac{\lambda\left(\lambda+\kappa^{2}\right)}{\kappa^{2}}\left\{\mathrm{E}_{1}\left[\left(u_{t}^{*}-\bar{u}\right)^{2} \mid \mathrm{c}\right]-\mathrm{E}_{1}\left[\left(u_{t}^{*}-\bar{u}\right)^{2} \mid \mathrm{n}\right]\right\},
\end{aligned}
$$

where $\mathrm{c}$ and $\mathrm{n}$ denote, respectively, crisis and non-crisis, and where the last term on the right side is zero and can be disregarded if the cost-push shock is independent of the crisis, which is the maintained assumption.

If instead the cost-push shock is assumed to be correlated with the crisis, that last term in (B.1) is exogenous but not zero and has to be included in the cost of a crisis. Furthermore, then $u_{t}^{*}$ is not independent of whether there is a crisis or not. With the non-crisis and crisis unemployment gaps satisfying $\tilde{u}_{t}^{\mathrm{n}} \equiv u_{t}^{\mathrm{n}}-u_{t}^{* \mathrm{n}}$ and $\tilde{u}_{t}^{\mathrm{c}} \equiv u_{t}^{\mathrm{c}}-u_{t}^{* \mathrm{c}}$, for them to satisfy $\tilde{u}_{t}^{\mathrm{c}}=\tilde{u}_{t}^{\mathrm{n}}+\Delta u_{t}, \Delta u_{t}$ has to satisfy $\Delta u_{t} \equiv\left(u_{t}^{\mathrm{c}}-u_{t}^{\mathrm{n}}\right)-\left(u_{t}^{* \mathrm{c}}-u_{t}^{* \mathrm{n}}\right)$. That is, $\Delta u$ is then defined as the crisis increase in the unemployment deviation and equals the crisis increase in the unemployment rate less the crisis increase in the benchmark unemployment rate. With these modifications, the analysis in the paper can be done also for a cost-push shock correlated with a crisis. ${ }^{33}$

\footnotetext{
${ }^{33}$ I am grateful to Simone Manganelli for alerting me to this issue.
} 


\section{A Markov process for crisis and non-crisis states}

Consider the situation in which the (quarterly) probability of a crisis start is $q$ and the crisis duration $n$ quarters. Assume for simplicity that a new crisis cannot start during an existing crisis, so the probability of crisis start is conditional on no crisis in the previous quarter. This situation can be modeled as a Markov process with $n+1$ states, where state 1 corresponds to a non-crisis and state $j$ for $2 \leq j \leq n+1$ corresponds to a crisis in its $(j-1)$ th quarter. ${ }^{34}$

Let the $(n+1) \times(n+1)$ transition matrix be $P=\left[P_{i j}\right]$, where $P_{i j}=\operatorname{Pr}(j$ in $(t+1) \mid i$ in $t)$ is the probability of a transition from state $i$ in quarter $t$ to state $j$ in quarter $t+1$. The transition probabilities will be zero except for $P_{11}=1-q, P_{12}=q, P_{i, i+1}=1$ for $2 \leq i \leq n$, and $P_{n+1,1}=1$. For example, for $n=3$ the $4 \times 4$ transition matrix is

$$
P=\left[\begin{array}{cccc}
1-q & q & 0 & 0 \\
0 & 0 & 1 & 0 \\
0 & 0 & 0 & 1 \\
1 & 0 & 0 & 0
\end{array}\right]
$$

Let the row vector $\pi_{t}=\left(\pi_{t i}\right)_{i=1}^{n+1}$ denote the probability distribution in quarter $t$, and let $\pi_{1}=(1,0, \ldots, 0)$, representing a non-crisis in quarter 1 . Then the probability distribution in quarter $t \geq 1$, conditional on a non-crisis in quarter 1 , is given by

$$
\pi_{t}=\pi_{1} P^{t}
$$

and the probability of crisis in quarter $t, p_{t}$, is given by

$$
p_{t}=1-\pi_{t 1} \text { for } t \geq 1 \text {. }
$$

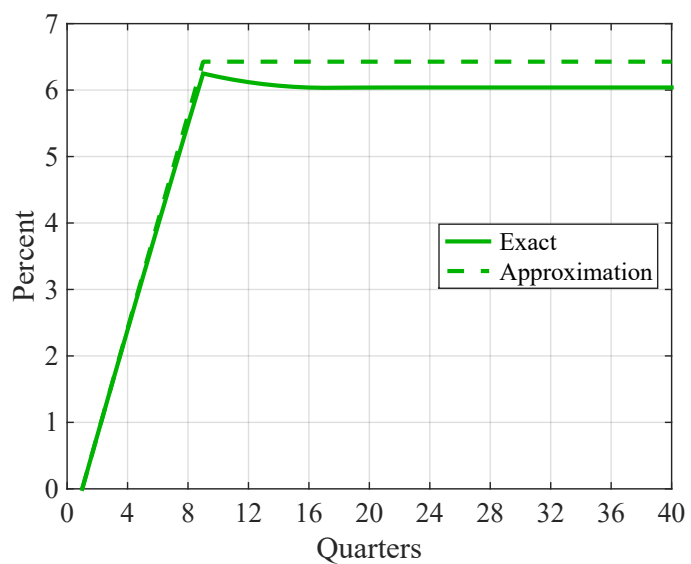

Figure C.1: The probability of a crisis in quarter by the Markov process for $q=0.8 \%$ and $n=8$ quarters and the linear approximation .

The solid green line in figure C. 1 shows the resulting probability of a crisis in quarter $t$, when $q=0.8 \%$ and $n=8$ quarters. The probability of a crisis rises to $6.25 \%$ and then falls back to $6 \%$. The dashed green line shows the probability of a crisis for the linear approximation when the probability of crisis is just the sum of the probabilities of a crisis start over the previous $n$ quarters,

$$
p_{t}=\sum_{\tau=0}^{n-1} q_{t-\tau} .
$$

\footnotetext{
${ }^{34}$ I am grateful for helpful discussions with Stefan Laséen and David Vestin on the Markov process of crisis and non-crisis states.
} 
The linear approximation increases to $6.4 \%$ and exaggerates the probability of a crisis somewhat. It was for simplicity used in Svensson (2016a).

The main advantage with the linear approximation (C.2), is that the policy-rate effect on the probability of a crisis is easy to calculate. Given the effect on the probability of a crisis start, $d q_{t} / d \bar{i}_{1}$ for $t \geq 1$, from figure 3.3 , it simply satisfies

$$
\frac{d p_{t}}{d \bar{i}_{1}}=\sum_{\tau=0}^{n-1} \frac{d q_{t}}{d \bar{i}_{1}} .
$$

For the Markov process, the calculation is a bit more complicated. Let $P_{t}=\left[P_{t, i j}\right]$ for $t \geq 1$, denote the transition matrix from states in quarter $t$ to states in quarter $t+1$, where $P_{t-1,11}=1-q_{t}$, $P_{t-1,12}=q_{t}$ and $P_{t-1, i j}=P_{i j}$ for $(i, j) \neq(1,1),(1,2)$. We have

$$
\pi_{t}=\pi_{t-1} P_{t-1} \text { for } t \geq 2 \text {. }
$$

Then policy-rate effect on the probability distribution satisfies

$$
\frac{d \pi_{t}}{d \bar{i}_{1}}=\frac{d \pi_{t-1}}{d \bar{i}_{1}} P_{t-1}+\pi_{t-1} \frac{d P_{t-1}}{d \bar{i}_{1}} \text { for } t \geq 2,
$$

where $d \pi_{1} / d \bar{i}_{1}=0, d P_{t-1,11} / d \bar{i}_{1}=-d q_{t} / d \bar{i}_{1}, d P_{t-1,12} / d \bar{i}_{1}=d q_{t} / d \bar{i}_{1}$, and $d P_{t-1, i j} / d \bar{i}_{1}=0$ for $(i, j) \neq(1,1),(1,2)$. Then

$$
\frac{d p_{t}}{d \bar{i}_{1}}=-\frac{d \pi_{t 1}}{d \bar{i}_{1}} \text { for } t \geq 2 .
$$

Svensson (2016a) shows that the linear approximation (C.3) of the derivative is relatively good for the range of parameters used here. Nevertheless, the exact derivative (C.4)-(C.6) is used in this paper.

\section{The logistic function}

Consider the logistic function

$$
q=\frac{\exp (a+b g)}{1+\exp (a+b g)}=\frac{1}{1+\exp [-(a+b g)]}
$$

where $q$ here is the annual probability of a crisis start, $g$ is a the steady annual growth rate of real debt and $a$ and $b$ are constants. In a logit regression of crises starts on current and lagged annual growth rates of real debt, $b$ corresponds to the sum of the coefficients on the lagged annual growth rates. 
The derivative of $q$ with respect to $g$, the marginal effect of steady real debt growth on the probability $q$, satisfies

$$
\frac{d q}{d g}=b q(1-q)
$$

The sum of coefficients in (3.2) is $b=9.698$. Given the $d q / d g=0.30$ reported by Schularick and Taylor (2012), it follows from (D.2) that $q=0.032$. (To be precise, the values used are $d q / d g=0.3016$ and $q=0.0321$.) Given $b$ and $q$, if $g=0.05$ it follows from (D.1) that $a=-3.890$.

Section 4 examines the case when $g=0.079$. Then $q=0.0421$, and $d q / d g=0.3914$. 